\title{
Revisiting potential physico-chemical hazards of ionic liquids
}

\author{
Alpha O. Diallo, ${ }^{\mathrm{a}, \mathrm{b}}$ Christophe Len, ${ }^{\mathrm{b}}$ Alexander B. Morgan, ${ }^{\mathrm{c}}$ Guy Marlair ${ }^{* \mathrm{a}}$ \\ ${ }^{a}$ Institut National de l'Environnement Industriel et des Risques (INERIS), Parc Technologique Alata, BP2, 60550, Verneuil-en-Halatte, France \\ ${ }^{b}$ UTC-ESCOM, EA 4297, Transformations Intégrées de la Matière Renouvelable, Centre de Recherches de Royallieu, BP 20529, F-60205 Compiègne Cedex, \\ France \\ c University of Dayton Research Institute (UDRI) - Kettering Laboratories, Room 562, 300 College Park, Dayton, Ohio 45469-0160, USA
}

\begin{abstract}
This paper is a consolidated overview of what was originally presented by the co-authors at the ILSEPT 2011 conference regarding physico-chemical safety issues pertaining to ionic liquids. Indeed safety performance of ionic liquids relating to physico-chemical hazards is very rarely investigated as it is often perceived as a non existing issue due to the lack of traditional flashpoint for these liquids. The paper outlines: a) why it is justified to have a detailed look of physicochemical properties of ionic liquids in the context of separation and purification technologies, b) sort out misleading from true general statements regarding actual safety, c) discuss physicochemical hazard rating systems and their limitation in the context of overall risk evaluation, and d) report on early finding of a joint initiative (carried out by INERIS, UTC, and UDRI) regarding the development of predictive tools for heats of combustion for ionic liquids and experimental results obtained by use of the pyrolysis combustion flow calorimetry (PCFC) on the effective rate of heat release from ionic liquids in fire conditions. Finally, perspectives regarding future work with regard to better knowledge and assessment of ionic liquid physico-chemical related issues are given with the aim of serving sustainable design and use of ionic liquids.
\end{abstract}

Keywords: Ionic liquids, physico-chemical hazards, heats of combustion, prediction models, rates of heat release.

\section{Introduction}

Ionic liquids (ILs) are a large class of low melting point organic salts that result from the combination of an organic cation and an organic or inorganic anion [1]. The term usually implies a melting point of $100{ }^{\circ} \mathrm{C}$ or lower, and many are liquid at room temperature. The wide range of potential combinations of cations and anions to yield ILs $\left(10^{18}\right.$ possibilities $)$ allows for a great variety of interactions and applications due to the tunable properties of the ILs. Already today several hundred of them have been synthesized. ILs are extensively investigated for many applications in various technological domains [2-10]. This includes solar cell applications, 
electrochemical storage, metal plating, extraction, separation and purification processes including biomass fragmentation - and propellant applications, to name a few. However, by contrast to the tremendously large number of ILs under interest, safety advantages keep being claimed in a very generic manner in terms of low vapour pressure (if not involatility), very good thermal stability, and absence of flammability property. Specifically, claims of ILs being "nonflammable" are hardly ever reported in appropriate context. As it results, ILs are sometimes denoted as "designer solvents" for chemistry and potential alternatives for the replacement of volatile conventional organic compounds traditionally and currently used in industrial processes.

\begin{tabular}{|c|c|c|c|c|}
\hline$R_{1}$ & $R_{1}$ & & Inorganic anions & Organic anions \\
\hline & & & $\mathrm{F}^{-}, \mathrm{Cl}^{-}, \mathrm{Br}^{-}$, & $\mathrm{CH}_{3} \mathrm{CO}_{2}^{-}, \quad \mathrm{CH}_{3} \mathrm{SO}_{4}^{-}$, \\
\hline & & & & $\mathrm{C}_{6} \mathrm{H}_{5} \mathrm{SO}_{3}^{-}(=\mathrm{OTs})$ \\
\hline ammoniun & phosphonium & pyrrolidinium & $\mathrm{BF}_{4}^{-}, \mathrm{PF}_{6}^{-}, \mathrm{SbF}_{6}^{-}, \mathrm{AsF}_{6}^{-}$ & $\mathrm{CF}_{3} \mathrm{CO}_{2}^{-}, \mathrm{C}\left(\mathrm{CF}_{3} \mathrm{SO}_{2}\right)_{3}^{-}$ \\
\hline & & $R_{1}$ & $\mathrm{NO}_{3}^{-}, \mathrm{ClO}_{4}^{-}$ & $\mathrm{CF}_{3} \mathrm{SO}_{3}^{-}(=\mathrm{OTf})$ \\
\hline & & & $\mathrm{Al}_{\mathrm{x}} \mathrm{Cl}_{(3 \mathrm{x}+1)}$ & $\mathrm{N}\left(\mathrm{SO}_{2} \mathrm{CF}_{3}\right)_{2}^{-}\left(=\mathrm{NTf}_{2}\right)$ \\
\hline & & & $\mathrm{Al}_{\mathrm{x}} \mathrm{Et}_{\mathrm{x}} \mathrm{Cl}_{(2 \mathrm{x}+1)}$ & \\
\hline & & & $\mathrm{CuCl}_{2}^{-}, \mathrm{AuCl}_{4}^{-}, \mathrm{ZnCl}_{3}^{-}$, & $\mathrm{BR}_{4}^{-}, \mathrm{R}_{3} \mathrm{BOH}^{-}$ \\
\hline imidazolium & triazolium & pyridinium & $\mathrm{SnCl}_{3}^{-}$ & \\
\hline
\end{tabular}

Figure 1. Chemical structures of some major key ionic liquids (left hand side: cations; right end side: anions)

The growing interest in both industrial and academic research on ILs, particularly in separation and purification technologies where nearly all families of ILs are concerned, has been done with the generic assumption that these chemicals are implicitly highly stable, non flammable, or safe to use in any process [11-13]. Due to the extreme variety in chemical composition (e.g. number of carbon atoms...), this statement is likely to suffer exceptions in the view of fire safety scientists and lead to inappropriate or lack of safety provision for their safe manufacturing, handling, storage and use. Despite the reputation of ILs as "green solvents", recent studies have already outlined the relative toxicity or eco-toxicity issues of some of the ILs used in practice [14-28]. INERIS and co-workers have identified that more appropriate evaluation of risks pertaining to ILs requires a focus on the potential physico-chemical hazards for a number of reasons: 
a) Open literature and commercial leaflets still contain misleading information on ILs in reporting too generally (or incorrectly) on volatility, flammability behaviours, and thermal stability.

b) The European Community Regulation on chemicals and their safe use, dealing with the Registration, Evaluation, Authorisation and Restriction of Chemical substances (REACH) [29] and the Classification Labelling and Packaging regulation (CLP) [30], demand more indepth analysis of physico-chemical risk evaluation.

c) First order evaluation of physico-chemical properties in relation with safety are needed in early stages of ILs design. In addition, there are relatively few experimental data available on physico-chemical properties of ILs in relation with physico-chemical intrinsic hazards; these information are however required for the design of processes and products involving these chemicals.

Ultimately, ILs are chemical compounds which are capable of a variety of chemical interactions depending upon the temperature, chemical environment, and atmosphere under which they are used. They cannot truly be considered as inert, and indeed, since many of them are carbon based, they are capable of sustaining combustion in the right fire risk scenario. Only by studying the physico-chemical properties of IL does it become possible to really begin to understand under what conditions ILs may chemically react that leads to an exothermic reaction, or, sustain enough thermal decomposition such that the IL ignites and burns. ILs are new technology however, and all new technology requires a closer look to really determine its safe use, as well as its strengths and weaknesses in the commercial or academic setting. ILs clearly have some key advantages that should be utilized and so this paper is not claiming these ILs as unsafe to use, but rather, a technology that should be studied further as it has not been correctly characterized to date. With that in mind, this paper illustrates general emerging issues relating to physico-chemical properties of ILs - not only limited to the flammability issue -, as well as first results obtained through modelling and testing towards a better appraisal the fire hazard risk profile.

\section{Sorting out myths from reality with ionic liquids}

Very often, technology is allowed to be inserted into commercial use via certification schemes put in place by regulatory codes and standards. Those schemes are often created by engineers and scientists who look at potential risk scenarios relevant to the technology at the time. Therefore, it is very common that when new technology is considered, it is measured with techniques and 
assessed with a scheme that may not always be correct, especially if the regulatory scheme is decades old and the original assumptions behind that scheme have been lost. Therefore, many regulatory schemes become reactive to new technologies rather than proactive, and the tests attempt to force-fit the new technology into the regulatory scheme. So in the case of most organic liquids (fuels, solvents), test such as flashpoint and boiling point become of primary concern, but with ILs, which technically have no vapour pressure or boiling point (they decompose before they boil); a flashpoint test is not at all relevant to assessing the fire safety of that material. Polyethylene has no boiling point or flashpoint, and yet is often considered to be a highly flammable solid. Therefore, for ILs, one must consider alternate assessments of fire risk. Since the material is a liquid and is known to thermally decompose, one must look to the ignition potential of the decomposition products, and should the material ignite, its ability to sustain ignition and generate heat. But this is merely a suggestion of what to consider. In reality, due to the very different physico-chemical properties of ILs, it is most likely that the entire fire risk scenarios associated with the use of these materials must be considered, and new tests relevant to those scenarios must be developed. In the end, a new regulatory scheme for safe use of ILs must be adapted. Just because something is considered to be safe under an older regulatory scheme does not mean it is always safe to use.

When considering a $1^{\text {st }}$ order evaluation of hazards pertaining to ILs, and partly linked with what has been said above is the use of inappropriate wording in describing the properties of ILs. Table 1 mention those wrong ways to report of hazards of ILs with in the right column a more consistent manner and correct wording to deal with same aspect. 
Table 1. Misleading and more correct statements about ionic liquids safety properties

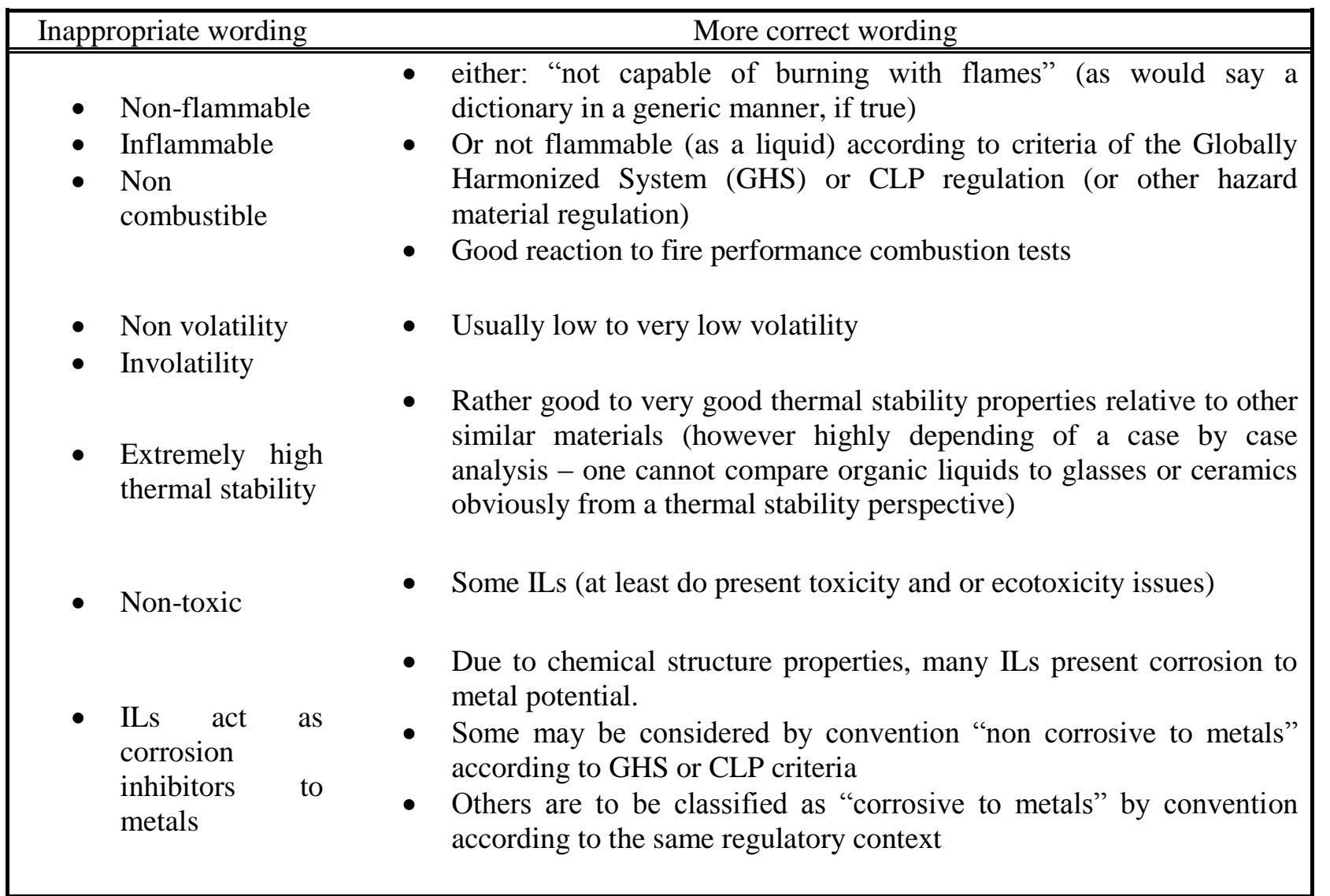

Notwithstanding above mentioned shortcomings about the way safety issues regarding ILs were assessed in the past and sometimes still are, the trend towards some progress has appeared in recent open literature. As a proof of this, a few early studies have been devoted to actually qualify physico-chemical hazards in dedicated and consistent way for some ILs [31-34]. As an outcome of those early studies, not all ILs can be considered intrinsically safe and nontoxic, and some may trigger risks during their synthesis. Indeed, in a lot of synthesis routes halogen atoms are involved. For some scientists, halogen materials in ILs are undesirable, because of the low hydrolytic stability, the high toxicity potential, the low biodegradability and the high disposal cost $[17,35,36]$.

Recent papers have also help to fight against the commonly reported non volatility and extreme thermal stability of ILs. As an example, Earle's study [37] showed that many ILs, particularly imidazolium-based ILs can be distilled (under partial vacuum) and their decomposition products are usually found to be volatile. Other researchers have addressed experimentally thermal stability properties of a number of ILs, showing that thermal stability up to $400^{\circ} \mathrm{C}$ or more is not 
the common rule for ILs and that in reality, thermal stability may vary greatly [38-41]. Some speakers at the ILSPET 2011 conference also pointed out that for some applications some ILs are not an option due to thermal stability issues $[42,43]$.

Beyond the issue of intrinsic physico-chemical potential issues of ILs, it is clear that "green solvent" character of ILs has to be appraised on the life cycle analysis and the environmental impact. In doing such an analysis, processing some ILs may be regarded - to some extent - at least more complex if not finally less green for environmental or safety reasons as compared to conventional solvents. Jessop [44] has shown this via a $1^{\text {st }}$ order indicator by considering the number of elemental process steps that are needed to produce ILs as compared to conventional flammable solvents. As an example, producing 1-butyl-3-methylimidazolium tetrafluoroborate require 32 elemental process steps against only 2 to produce methanol.

\section{Conventional vs. real life hazard assessment}

\subsection{Conventional schemes for hazards classification}

Recently, changes have been made in chemicals hazards classification in the European Union. At the international level, the United Nations (UN) has developed the so called GHS system, aiming at harmonizing classification of hazardous materials at a worldwide level. In the European Union, the CLP has been implemented on the $1^{\text {st }}$ Jan 2009, as the local transposition of the GHS. In the CLP, new methods associated with new criteria induce a more detailed classification of physical hazards of substances and mixtures as compared to preceding regulation scheme. The application of CLP implies, in the case of physical hazard, the transposition from the 5 categories of hazards in the old European classification system (67/548/EEC) to newly established 16 classes of hazards originating from the GHS. Some categories of hazards are modified - through modified criteria or new method for testing - and new classes of hazards have appeared, as illustrated in Figure 2. Thus, the regulatory environment for risk control involves at least a new rigor in the identification of "conventional" physico-chemical hazards. A real thorough assessment of physico-chemical hazards that may involve the use of ILs should reflect these new changes and requires a detailed analysis, owing to great variety of ILs chemical structures and taking account of the degree of relevance of classes of hazards for ILs. Even the initial physical state of ILs (that needs to take account of ambient temperature conditions) keeps an open issue in some cases (as all ILs are not liquid at room temperature or quickly solidify just below room temperature). 


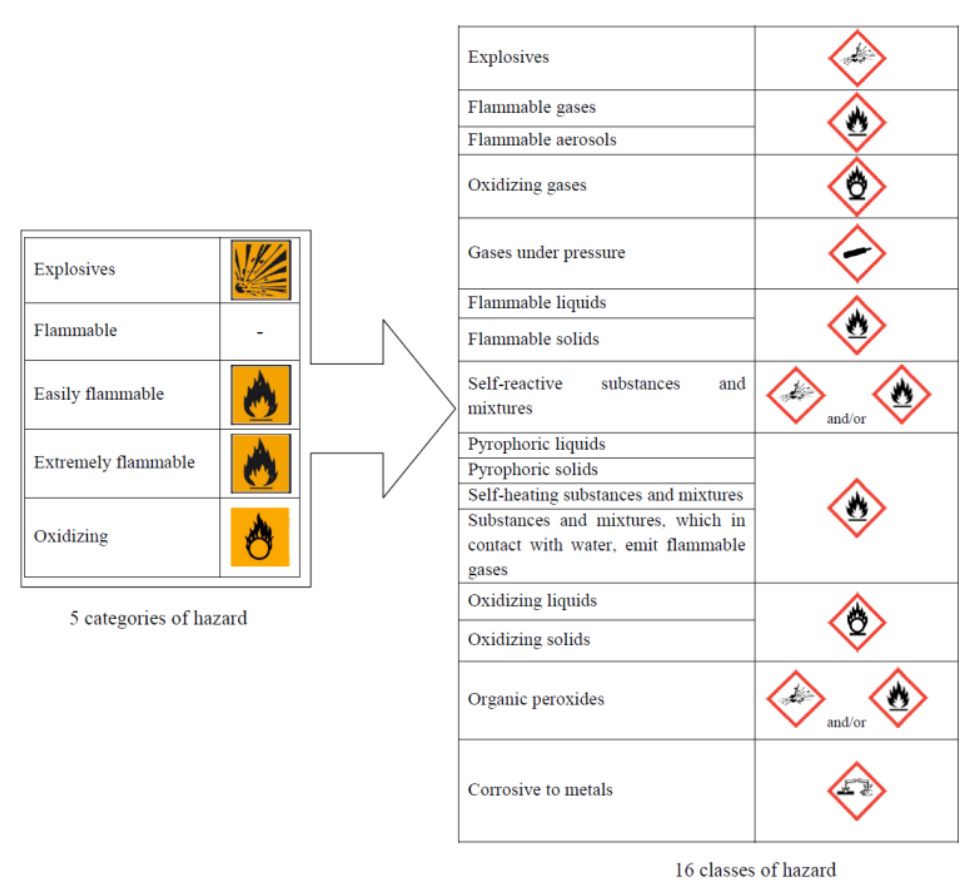

Figure 2. Recent regulatory move in physico-chemical hazards classification from 5 categories of hazard to 16 classes of hazard described, as implied in the CLP

\subsection{Limitations of hazard classification systems}

Some of them have been outlined in section 3.1. Conventional hazards are needed to define physico-chemical hazards properties from a regulatory viewpoint, but there are important limitations of using these methods because:

a) conventions are changing versus time (e.g. CLP versus Substance Directive 67/548/EEC),

b) conventions are not the same in all countries,

c) conventions provide a simplified view of the actual hazards which is a limitation per se if considered too abruptly.

For insistence, the flashpoints are not defined the same way in the CLP regulations and in the US Occupational Safety and Health Administration (OSHA) regulations. In EU regulation, flammable liquids means any liquids having flashpoint at $60^{\circ} \mathrm{C}$, in $\mathrm{GHS}$ the flashpoint is between $60^{\circ} \mathrm{C}$ and $93^{\circ} \mathrm{C}$ for flammable liquid category 4 , whereas in the US the flashpoint must be below $37.8^{\circ} \mathrm{C}$. However, for fire risk prevention, OSHA also considers the term of "combustible liquids" any liquid having a flashpoint at or above $37.8^{\circ} \mathrm{C}(e . g$. virtually all liquids not qualified as flammable). All these values couldn't change anything for ILs, but actual profile hazards are different to the conventional hazards in so far as "non-flammable" products may burn with 
flames depending on environmental conditions (atmosphere, heat, ignition sources...). Another example of limitation in conventional hazard rating lies in the procedure applying for the metal corrosion ability of a material.. Corrosivity to metal is indeed a new property taken in consideration in the CLP system. Conventional "corrosive to metals property" as defined in GHS (2002) and CLP (2009) stands for substances or mixtures which by chemical action will materially damage or even destroy metals, but criteria are only fixed for uniform and pitting corrosion on steel and aluminium, which inherently contain a double limitation in terms of metal portfolio under consideration and also as regard the corrosion process. Some ILs are likely to be corrosive to other metals although they are "non corrosive" to steel and aluminium [14,45-52]. The nature of common anions in use $\left(\mathrm{BF}_{4}^{-}, \mathrm{PF}_{6}^{-}, \mathrm{Cl}, \mathrm{Br}^{-}, \mathrm{CF}_{3} \mathrm{SO}_{3}{ }^{-} \ldots\right)$ for separation and purification techniques may reasonably raise that this is a real issue for at least some of those ILs. One could foresee a problem when ILs are used in battery or electrochemical applications and the metals on the anode and cathode corrode in contact with the IL.

Last, but not least, incompatibilities between chemicals are not within the scope of hazards materials classification regulations, but they shall not be ignored in the hazard assessment of physico-chemical properties of ILs. The more trivial example of that is the hydrophobicity of some ILs (not a generic rule) but some of the anions are highly acidic were they to be protonated which could lead to some oxidizer-type chemical reactions at elevated temperature.

\subsection{Lessons from incidents and recent safety-oriented research}

Although "not flammable", some ILs have been observed burning with flames accidentally in laboratories, moreover, self sustained or piloted combustion of some ILs have been shown as a potential incidental scenario in some experiments. In most cases, rapid exothermic decomposition occurs when ILs with high nitrogen content are taken to high temperature and the subsequent decomposition products are sensitive to ignition and combustion. The combustion may even tend to be explosive even under vacuum as shown by Smiglak [31] for imidazolium-based ILs or hydrazinium-based ILs tested in their works. In addition, burning tests performed on 4-Amino-1methyl-1,2,4-triazolium nitrate by Schaller [33] have led to flame temperature of 2,200 K. In some cases ILs are even combustible by design where intended for use as propellants as alternatives to hydrazine $[53,54]$. Ultimately, once the various molecular bonds reach their thermal decomposition temperature in these carbon-based ILs, any number of flammable small 
molecules could be release leading to combustion. These examples show again that the flashpoint is certainly not enough to characterize the fire hazard.

Flammability issues may also arise from specific behaviour of hypergolic ILs in which in contact with the dinitrogen tetroxide $\left(\mathrm{N}_{2} \mathrm{O}_{4}\right)$ or white fuming nitric acid (WFNA) can spontaneously ignite due to the highly exothermic reaction that takes place. It was shown that ILs with the dicyanamide or nitrocyanamide anion in particular are hypergolic [10,55-58]. Also, 2,2dimethyltriazanium nitrate and 2,2-dimethyltriazanium chloride are hypergolic prone materials [55], suggesting that also the nature of the cation of the IL can modify hypergolic properties.

Many different processes using ILs may lead to metal corrosion. Indeed many papers have reported the instability of ILs contained $\mathrm{PF}_{6}^{-}$anion towards hydrolysis in contact with moisture, forming volatiles compounds including $\mathrm{HF}$ and $\mathrm{POF}_{3}$ which are known to damage materials such as steel and glass [14,45-48].

Tseng [49] recently showed excellent resistance to corrosion of stainless steel 304SS against chloride-1-ethyl-3-methylimidazolium chloride, whereas same IL severely corrodes titanium. In his researches about the use of ILs in high pressure applications, Predel [50,51] observed that even when all of the tested ILs showed very low corrosiveness to stainless steel, the corrosion rates of some ILs to steel and cupriferous materials were too high. He concluded that many ILs are definitely not suitable in an application where copper is involved.

The effect of temperature on corrosion properties of 1-butyl-3-methyl-imidazolium bis(trifluoromethanesulfonyl)imide has also been studied by Perissi [52] who has shown that an increase in temperature may lead to corrosion of several metals and metal alloys (copper, nickel, AISI 1018 steel, brass, Inconel 600).

The corrosivity for a given metal is determined by the chemical structure of the IL cation and the nature of the anion. The results obtained indicate that materials selection for technical equipment used in IL-based chemical processes is a very important issue and requires further investigations with respect to chemical and electrochemical corrosion mechanisms and its relation to the chemical structure and concentration of ILs.

The impurity levels of ILs are also issues that have to be taken in account because they considerably affect both the physico-chemical and electrochemical properties of ILs. Tetsuya [59] showed that the addition of water to 1-ethyl-3methylimidazolium chloride results in 
a violent reaction with the evolution of heat and $\mathrm{HCl}$ gas and an obvious change in the appearance of the IL. In his work, Smiglak [31] suspected that impurities in the trihexyltetradecylphosphonium chloride are responsible for ignition spray even as this IL was said to be stable over $300^{\circ} \mathrm{C}$.

In view of all these findings, and although so far no major accident has been reported with ILs at the current stages of use, it seems pertinent to develop systematic and comprehensive methodologies of determining hazardous profiles of ILs. Thus, focus on the development of reliable simple methods for predicting heats of complete combustion of ILs has been done as a starting point for a more comprehensive consideration of safe use of ILs in the context of green chemistry and biorefining.

\section{Early findings dealing with the fire hazard}

\subsection{Prediction of heats of combustion}

Complete heat of combustion (high heating values -HHV- or low heating values -LHV) is one of the first indicators used to pre-assess potential fire hazards of a chemical substance. It represents the overall energy content that a substance is liable to release by complete combustion in a fire event.

For that purpose, an overview of 18 existing empirical correlations giving heats of combustion developed in early times of combustion science has been performed and re-examined in a scientific-sound manner for their ability to predict heats of combustion of ILs. These models were based on structure-property relationships, in which structure was simply described by elemental mass composition descriptors and related models obtained from multilinear regression techniques. As those 18 empirical correlations have clearly been established and validated against products data excluding the case of ILs (the oldest dates from, the youngest dates from), we have compiled thermodynamic data of some 53 ILs covering 8 families of most common ILs in a new

database that has served as validation sets. Per se, such an exercise was not trivial and showed us the extreme difficulty to access thermodynamic data in the open literature. For example, in the IUPAC Ionic Liquids Database website [60], there are no data at all available for heats of combustion of ILs. From the examination of the 18 correlations, 5 of those were revealed to be quite effective for predicting reasonable heats of combustion of ILs $\left(\mathrm{R}^{2}>0.94\right)$. These models are described in Table 2. Moreover, the database was also used to develop a fully-dedicated model 
according to the OECD principles for regulatory acceptability [61], which expressly requires an external validation process.

The same database compiling measured heats of combustion of 53 ILs was used this time differently by splitting the data into a training set (to establish parameters of the new model with same descriptors as those of the previously 18 correlation examined) and a validation set. This work has been detailed in another paper submitted recently elsewhere [62].

Not surprisingly, the new model works even slightly better and opens the route for addressing brand new ILs that would require special focus.

Table 2. Predictive powers of the top 5 existing models

\begin{tabular}{|llcc|}
\hline No & Correlation & \% error & $\mathrm{R}^{2}$ \\
\hline \hline 1 & Boie & 4.6 & 0.97 \\
2 & Dulong-Berthelot & 6.4 & 0.94 \\
3 & Garvin & 4.9 & 0.96 \\
4 & Gumz & 4.1 & 0.97 \\
5 & Lloyd-Davenport & 3.2 & 0.98 \\
\hline
\end{tabular}

Figure 3 plots predicted values of heats of combustion from ILs in our database, grouped by family of ILs, showing how far heats of combustion may vary. As an example, in the case of imidazolium-based ILs, the heats of combustion vary quite significantly from some $15 \mathrm{MJ} / \mathrm{kg}$ up to $35 \mathrm{MJ} / \mathrm{kg}$. This finding suggests complete combustion of some ILs is found comparable to those pertaining to many usual combustible or flammable materials.

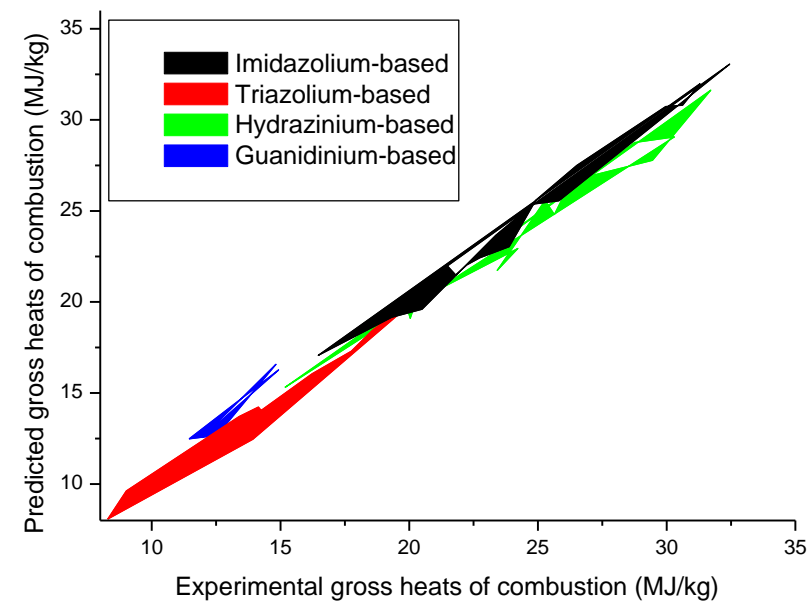

Figure 3. Predicted vs. reported gross heats of combustion for ionic liquids based on the dedicated-model (taken from ref. [62]) 
In Table 3, the model predictability has been use to pre-assess combustibility property of ILs not present in our database. As can be seen, the values of heats of combustion expand even larger, showing for some of them, values far exceeding the upper limit of ILs that were originally in our database. In particular, phosphonium-based ILs looks potentially very energetic which claim from further assessment of effective rates of heat release that can only be obtained by experiments.

Table 3. Predictability of heats of combustion of some ionic liquids using the purpose-built model

\begin{tabular}{|lllc|}
\hline Chemical Name & Synonym & Formula & $\begin{array}{l}\text { Predicted values of heats } \\
\text { of combustion (MJ/kg) }\end{array}$ \\
\hline \hline $\begin{array}{l}\text { 1-ethyl-3-methylimidazolium bromide } \\
\text { 1-ethyl-3-methylimidazolium } \\
\text { trifluoromethanesulfonate }\end{array}$ & emim Br & $\mathrm{C}_{6} \mathrm{H}_{11} \mathrm{BrN}_{2}$ & 20,2 \\
1-ethyl-3-methylimidazolium acetate & emim otf & $\mathrm{C}_{7} \mathrm{H}_{11} \mathrm{~F}_{3} \mathrm{~N}_{2} \mathrm{O}_{3} \mathrm{~S}$ & 15,3 \\
$\begin{array}{l}\text { 1-butyl-3-methylimidazolium } \\
\text { hexafluorophosphate }\end{array}$ & emim ac & $\mathrm{C}_{8} \mathrm{H}_{14} \mathrm{~N}_{2} \mathrm{O}_{2}$ & 29,6 \\
$\begin{array}{l}\text { N-butylpyridinium tetrafluoroborate } \\
\text { 1-butyl-3-methylimidazolium }\end{array}$ & bmim PF6 & $\mathrm{C}_{8} \mathrm{H}_{15} \mathrm{~F}_{6} \mathrm{~N}_{2} \mathrm{P}$ & 17,8 \\
$\begin{array}{l}\text { bis(trifluoromethylsulfonyl)amide } \\
\text { N-butyl-N-methylpyrrolidinium } \\
\text { trifluoromethanesulfonate }\end{array}$ & bpyr BF4 & $\mathrm{C}_{9} \mathrm{H}_{14} \mathrm{BF}_{4} \mathrm{~N}$ & 24,1 \\
$\begin{array}{l}\text { 1-butyl-2,3-dimethylimidazolium } \\
\text { bis(trifluoromethylsulfonyl)amide }\end{array}$ & bmim ntf & $\mathrm{C}_{10} \mathrm{H}_{15} \mathrm{~F}_{6} \mathrm{~N}_{3} \mathrm{O}_{4} \mathrm{~S}_{2}$ & 13,2 \\
$\begin{array}{l}\text { 1-hexyl-3-methylimidazolium } \\
\text { trifluoromethanesulfonate }\end{array}$ & bmpl otf & $\mathrm{C}_{10} \mathrm{H}_{20} \mathrm{~F}_{3} \mathrm{NO}_{3} \mathrm{~S}$ & 21,7 \\
N-butyl-N-methylpyrrolidinium dicyanamide \\
tributylethylphosphonium diethylphosphate \\
$\begin{array}{l}\text { triisobutyl(methyl)phosphonium p- } \\
\text { toluenesulfonate } \\
\text { trihexyl(tetradecyl)phosphonium chloride } \\
\text { trihexyl(tetradecyl)phosphonium bromide } \\
\text { trihexyl(tetradecyl)phosphonium dicyanamide }\end{array}$ & bmmim ntf & $\mathrm{C}_{11} \mathrm{H}_{17} \mathrm{~F}_{6} \mathrm{~N}_{3} \mathrm{O}_{4} \mathrm{~S}_{2}$ & 14,3 \\
\hline
\end{tabular}

\subsection{Early findings on rates of heat releases}

In 2008, studies were conducted to assess the heat release of ILs via pyrolysis combustion flow calorimetry (PCFC), which is a small scale oxygen consumption calorimetry test [34]. This was done because at the time, the ILs were all shown to have no flashpoint, and yet from a physicochemical perspective, it was clear that these salts did have chemical structures capable of releasing heat if they were thermally decomposed and exposed to oxidizing conditions. Therefore some quick assessment of ILs was conducted, using the PCFC method to quantify heat release in relation to the chemical structure of the ionic liquid. 
Before explaining the results on heat release further, some discussion of the PCFC technique is needed. The PCFC is a standard method (ASTM D7309) for measuring the heat release via oxygen consumption calorimetry at the 5-50mg sample size, making it a potent technique for quantification of material flammability without consuming large amounts of material. This technique has been shown to quantify the heat release for a wide range of solids (i.e. - materials without an obvious flashpoint) [63-69] and therefore was thought to be a relevant test to measure the heat release of ILs. Within the PCFC technique there are two potential measurements. The first measurement is where the sample is heated under nitrogen at $1{ }^{\circ} \mathrm{C} / \mathrm{second}$. This is referred to as Method A under ASTM D7309, and it roughly mimics what happens in a real fire post ignition (where oxygen is consumed at the flame front). The second measurement is where the sample is heated under air (a synthetic $80 \% \mathrm{~N}_{2} / 20 \% \mathrm{O}_{2}$ blend) at $1{ }^{\circ} \mathrm{C} /$ second. This is referred to as Method B within ASTM D7309, and it give a heat release measurement equivalent to the heat of combustion for a material. So with the PCFC, one can obtain fundamental heat release data for a material as a function of its chemical structure, and can study heat release rates versus temperature, as well as heat of combustion behaviour. So with that information, we studied the heats of combustion and heat release behaviour of several ILs using Method B of ASTM D7309. The results from these experiments are shown in Table 4 below.

Table 4. Heat of combustion data for ionic liquids tested with the PCFC.

\begin{tabular}{|lcccc|}
\hline Sample & $\begin{array}{c}\text { Char Yield } \\
(\mathrm{wt} \%)\end{array}$ & $\begin{array}{c}\mathrm{HRR}^{(*)} \text { Peak(s) } \\
(\mathrm{W} / \mathrm{g})\end{array}$ & $\begin{array}{c}\text { Total HR } \\
(\mathrm{kJ} / \mathrm{g})\end{array}$ & $\begin{array}{c}\text { Predicted } \\
\text { HHV (kJ/g) }\end{array}$ \\
\hline \hline 1-butyl-3-methylimidazolium tetrafluoroborate & 0.29 & $306-194$ & 27.7 & 22.9 \\
1-butyl-2,3-dimethylimidazolium tetrafluoroborate & 1.08 & $381-327$ & 22.6 & 25.6 \\
$\begin{array}{l}\text { 1-butyl-3-methylimidazolium hexafluorophosphate } \\
\text { 1-butyl-2,3-dimethylimidazolium }\end{array}$ & 1.41 & $333-149$ & 15.1 & 17.8 \\
$\begin{array}{l}\text { bis(trifluoromethylsulfonyl)amide (TFSI) } \\
\text { 1-butyl-2,3-dimethylimidazolium dicyanamide }\end{array}$ & 2.29 & $209-111$ & 11.4 & 14.3 \\
$\begin{array}{l}\text { (N(CN)2) } \\
\text { 1-hexadecyl-2,3-dimethylimidazolium chloride }\end{array}$ & 3.82 & $371-341$ & 17.6 & 31.9 \\
$\begin{array}{l}\text { 1-hexadecyl-2,3-dimethylimidazolium bromide } \\
\text { 1-hexadecyl-2,3-dimethylimidazolium }\end{array}$ & 0.00 & 1638 & 34.2 & 40.8 \\
hexafluorophosphate & 12.70 & 594 & 20.5 & 35.6 \\
$\begin{array}{l}\text { 1-butyl-2,3-dimethylimidazolium chloride } \\
\text { 1-butyl-2,3-dimethylimidazolium bromide }\end{array}$ & 0.14 & 753 & 26.6 & 30.2 \\
$\begin{array}{l}\text { 1-butyl-2,3-dimethylimidazolium } \\
\text { hexafluorophosphate }\end{array}$ & 0.00 & 344 & 17.3 & 32.0 \\
\hline
\end{tabular}

$(*):$ HRR $=$ Heat of Heat Release (in terms of specific power ;

(**) Total effective heat release (in terms of specific energy) 
For comparison, table 4 also indicated in last column predictive values of complete heats of combustion. From the table it comes out that only a fraction (between 55\% to 90\%) is liberated in our experimental conditions (if we exclude the case of 1-butyl-3-methylimidazolium tetrafluoroborate for which the apparent incoherence has not been investigated at this stage). From this study, there are several useful conclusions that could be made. In general, the more carbon in the ILs structure, the more heat release generated by the material when it burned. Further, counterion had a definite effect on flammability, with the general trend of $\mathrm{Cl}<\mathrm{Br}<\mathrm{N}(\mathrm{CN})_{2}<\mathrm{BF}_{4}=\mathrm{PF}_{6}<\mathrm{TFSI}$ when looking at which counterion reduced heat release the most. One could argue that some of the counterions not only reduce the fuel available for combustion through char formation, but they also may be capable of unusual gas phase reactions which inhibit combustion and oxygen consumption. Indeed, up to $800^{\circ} \mathrm{C}$, many materials left behind thermally stable char under the oxidative conditions of the test.

Along with the measured total heat release (which under ASTM D7309, Method B is equal to heat of combustion), heat release rate peak values were studied. Some of the ILs yielded simple single peak/event decompositions and heat release, while others were more complex. Again the counterion changed the condensed phase decomposition of the material. A dramatic example of this would be comparing the $\mathrm{DMBI}_{-} \mathrm{BF}_{4}$ to the $\mathrm{DMBI}-\mathrm{Cl}$ which show greatly different heat release profiles. So with the PCFC, one can measure the heats of combustion of liquids that have no flashpoint while also studying their heat release/decomposition profiles which are affected by chemical structure.

While the PCFC showed some useful insight into the flammability of these materials, the technique did have some shortcomings in analyzing these materials. The first was that sample mass of the liquids tested had some noticeable effects on the precision of the data collected. ILs do absorb water rapidly which changes their sample mass from a char yield and flammable mass perspective. Further, metering out 5-15mg of ILs repeatedly for this test did prove difficult and likely led to some of the observed scatter in the data. Therefore some improvements in sampling would be needed to get better data for future ILs flammability studies.

To conclude, the use of PCFC enabled the quantification of heat release potential and gave some useful insight into chemical structure of ILs and their potential flammability. The chemical structure of the cation and anion of the ILs can have a big effect on heat release, and therefore one must not assume that all ILs are the same from a flammability perspective. The potential for 
some ILs to char may have some unexpected effects on flame spread, just as the potential for other ILs to fully gasify may also change what happens in a larger scale fire. Heat release is only one of many potential things to consider, and while it tells the fire safety engineer and chemist a great deal of information about flammability potential, it does to reveal everything. Clearly, more study is needed, but, heat release measurements like that from the PCFC are a place to start when making an assessment on the fire safety of this new technology.

\section{Conclusions and Perspectives}

In most cases, ILs have a lot advantages towards safer separation and purification processes compared to conventional solvents, and this is a fact that no one denies. But saying that ILs are safe by nature as a general statement can be seen as a hasty conclusion. There are some physicochemical safety issues and we should try to remove the misleading wordings such as "non flammability", "non volatility" since the recent literature refers to volatile decomposition of ILs. Corrosivity must be regarded as an important issue and chemical incompatibilities have to be considered. Like all new technologies, more time is needed to properly assess the strengths and weaknesses of this new technology, and better understand and assign safety performance parameters appropriate to the chemistry and physical properties of this new class of materials.

It seems also obvious from lectures that were given at the ILSEPT conference that the chemical structures play a major role in the value of heats of combustion (hence on physico-chemical issues) as well as toxicity and ecotoxicity issues. Some design techniques such as limiting the size of side chains on the cation part may in the same time favor the reduction of toxicity and flammability, but ultimately it will involve chemical research to establish the chemical structureproperty relationships that yield an IL with a favorable reactive, flammability, toxicity, cost and performance profile. Very likely future ILs will have a balance of properties and clear direction will be given on how that specific IL can and cannot be used relative to its physico-chemical properties.

It is also important to go beyond conventional hazard ratings for a better understanding of the physico-chemical properties of ILs. As discussed in the study, heats of combustion of ILs are often close or in the order of those of conventional combustible materials like wood, or plastics. Just as one does not compare all chemical compounds with the same metric, ILs must not be compared exactly with industrial solvents because they are very different chemicals. Certainly 
they have their advantages, but they are flammable and once it understood under what conditions they can burn, better fire safety assessments can be conducted. Fire hazards in processes have to be further investigated, because maybe those chemicals are not flammable due to the flashpoint, but in some processes or some applications we can have potential heats released that will serve to ignite them.

For that purpose, work has been initiated to develop a dedicated methodology to qualify risk profiles of ILs to be encouraged. Huge number of ILs dictates use of both experimentation and development of predictive tools using molecular modeling, and we believe some of the tools outlined in this paper, simple predictive heat of combustion modeling and the use of PCFC, could be a very good place to start in providing a more realistic heat release / fire risk profile for this new class of materials.

\section{Literature}

[1] M. Earle, A. Forestier, H. Olivier-Bourbigou, P. Wasserscheid, Ionic Liquids in Synthesis, ed. P. Wasserscheid and T. Welton, Wiley-VCH, Weinheim, 2003.

[2] B. Kirchner, Ionic Liquids. Topics in Current Chemistry, Springer-Verlag, Berlin, 1st Edition, 2010.

[3] S. J. Zhang, X. P. Zhang, Y. S. Zhao, G. Y. Zhao, X. Q. Yao, H. W. Yao, A novel ionic liquids-based scrubbing process for efficient CO2 capture, Sci. China Chem. 53 (2010) $1549-1553$.

[4] H. Sakaebe, H. Matsumoto, K. Tatsumi, Application of room temperature ionic liquids to Li batteries, Electrochim. Acta. 532007 1048-1054.

[5] S. Zhu, Dissolution of cellulose with ionic liquids and its application: a mini-review. Green Chem. 8 (2006) 325-327.

6] Y. Wang, H. Li, C. Wang, H. Jiang, Ionic liquids as catalytic green solvents for cracking reactions, Chem. Commun. 2004 1938-1939.

[7] C. Roosen, P. Müller, L. Greiner, Ionic liquids in biotechnology: applications and perspectives for biotransformations, Appl Microbiol Biotechnol. 81 (2008) 607-614.

[8] N. V. Likhanova, D. Guzmán-Lucero, E. A. Flores, P. García, M. A. Domínguez-Aguilar, J. Palomeque, R. Martínez-Palou, Ionic liquids screening for desulfurization of natural gasoline by liquid-liquid extraction. Mol Divers. 14 (2010) 777-787.

[9] T. C. R. Brennan, S. Datta, H. W. Blanch, B. A. Simmons, B. M. Holmes, Recovery of Sugars from Ionic Liquid Biomass Liquor by Solvent Extraction, Bioenerg. Res. 3 (2010) $123-133$. 
10] T Hawkins, M. Rosander, G. Vaghjiani, S. Chambreau, G. Drake, S. Schneider, Ionic Liquids as Hypergolic Fuels, Energ. Fuel 22 (2008) 2871-2872.

[11]H. L. Ngo, K. LeCompte, L. Hargens, A. B. McEwen, Thermal properties of imidazolium ionic liquids, Thermochim. Acta. 357-358 (2000) 97-102.

[12]P. Bonhôte, A. P. Dias, N. Papageorgiou, K. Kalyanasundaram, M. Grätzel, Hydrophobic, Highly Conductive Ambient-Temperature Molten Salts, Inorg. Chem. 35 (2011) 1168-78.

[13]A. B. McEwen, H. L. Ngo, K. LeCompte, J. L. Goldman, Electrochemical Properties of Imidazolium Salt Electrolytes for Electrochemical Capacitor Applications, J. Electrochem. Soc. 146 (1999) 1687-95.

[14] R. P. Swatloski, J. D. Holbrey, R. D. Rogers, Ionic liquids are not always green: hydrolysis of 1-butyl-3-methylimidazolium hexafluorophosphate, Green Chem. 5 (2003) 361-363.

[15]C. Pretti, M. Renzi, S. Ettore Focardi, A. Giovani, G. Monni, B. Melai, Sunita Rajamani, Cinzia Chiappe, Acute toxicity and biodegradability of $\mathrm{N}$-alkyl-N-methylmorpholinium and $\mathrm{N}$-alkyl-DABCO based ionic liquids, Ecotoxicol. Environ. Saf. 74 (2011) 748-753.

[16]D. J. Couling, R. J. Bernot, K. M. Docherty, J. K. Dixon, E. J. Maginn, Assessing the factors responsible for ionic liquid toxicity to aquatic organisms via quantitative structure-property relationship modeling, Green Chem. 8 (2006) 82-90.

[17] M. T. Garcia, N. Gathergood, P. J. Scammells, Biodegradable ionic liquids: Part II. Effect of the anion and toxicology, Green Chem. 7 (2005) 9-14.

[18] J. Jodynis-Liebert, M. Nowicki, M. Murias, T. Adamska, M. Ewertowska, M. Kujawska, H. Piotrowska, A. Konwerska, D. Ostalska-Nowicka, J. Pernak, Cytotoxicity, acute and subchronic toxicity of ionic liquid, didecyldimethylammonium saccharinate, in rats, Regul. Toxicol. Pharmacol. 57 (2010) 266-273.

[19] M. M. Bailey, M. B. Townsend, P. L. Jernigan, J. Sturdivant, W. L. Hough-Troutman, J. F. Rasco, R. P. Swatloski, R. D. Rogers, R. D. Hood, Developmental toxicity assessment of the ionic liquid 1-butyl-3-methylimidazolium chloride in CD-1 mice, Green Chem. 10 (2008) 1213-1217.

[20]T. P. T. Pham, C. W. Cho, Y. S. Yun, Ecotoxicological effects and biodegradability of ionic liquids associated with imidazolium and pyridinium cations, The Korean Society of Industrial and Engineering Chemistry, Kie-Myeoung University, Daegu, 2007 (Oral presentation).

[21] S. H. Wang, P. P. Huang, X. Y. Li, C. Y. Wang, W. H. Zhang, J. J. Wang, Embryonic and developmental toxicity of the ionic liquid 1-methyl-3-octylimidazolium bromide on goldfish, Environ. Toxicol 25 (2009) 243-50.

[22]T. P. T. Pham, C. W. Cho, Y. S. Yun, Environmental fate and toxicity of ionic liquids: A review, Water Research. 44 (2010) 352-72.

[23]P. Stepnowski, A. C. Skladanowski, A. Ludwiczak, E. Laczyńska, Evaluating the cytotoxicity of ionic liquids using human cell line HeLa, Hum. Exp. Toxicol. 23 (2004) 513517.

[24]B. Jastorff, R. Störmann, J. Ranke, K. Mölter, F. Stock, B. Oberheitmann, W. Hoffmann, J. Hoffmann, M. Nüchter, B. Ondruschka, J. Filser, How hazardous are ionic liquids? 
Structure-activity relationships and biological testing as important elements for sustainability evaluation, Green Chem. 5 (2003) 136-42.

[25]A. Romero, A. Santos, J. Tojo, A. Rodriguez, Toxicity and biodegradability of imidazolium ionic liquids, J. Hazard. Mater. 151 (2008) 268-273.

[26] K. M. Docherty, C. F. Kulpa Jr, Toxicity and antimicrobial activity of imidazolium and pyridinium ionic liquids, Green Chem. 7 (2005) 185-189.

[27] A. Latała, M. Nędzi, P. Stepnowski, Toxicity of imidazolium and pyridinium based ionic liquids towards algae. Bacillaria paxillifer (a microphytobenthic diatom) and Geitlerinema amphibium (a microphytobenthic blue green alga), Green Chem. 11 (2009) 1371-1376.

[28] K. J. Kulacki, G. A. Lamberti, Toxicity of imidazolium ionic liquids to freshwater algae, Green Chem. 10 (2008) 104-110.

[29] The European Commission Website on Registration, Evaluation, Authorisation and Restriction of Chemicals (http://ec.europa.eu/enterprise/sectors/chemicals/reach/index_en.htm) (Accessed July 2011).

[30] Regulation (EC) No 1272/2008 of the European Parliament and of the Council of 16 December 2008 on Classification, labelling and packaging of substances and mixtures, mending and repealing, European Parliament and of the Council, Directives 67/548/EEC and 1999/45/EC, and amending Regulation (EC) No 1907/2006. (http://eurlex.europa.eu/LexUriServ/LexUriServ.do?uri=CONSLEG:2008R1272:20101201:EN:PDF) (Accessed July 2011).

[31] M. Smiglak, W. M. Reichert, J. D. Holbrey, J. S. Wilkes, L. Sun, J. S. Thrasher, K. Kirichenko, S. Singh, A. R. Katritzky, R. D. Rogers, Combustible ionic liquids by design: is laboratory safety another ionic liquid myth?, Chem. Commun. (2006) 2554-2556.

[32]D. M. Fox, W. H. Awad, J. W. Gilman, P. H. Maupin, H. C. De Long, P. C. Trulove, Flammability, thermal stability, and phase change characteristics of several trialkylimidazolium salts, Green Chem. 5 (2003) 724-727.

[33]U. Schaller, T. Keicher, V. Weiser, H. Krause, S. Schlechtriem, Synthesis, Characterization and Combustion of Triazolium Based Salts, Insensitive munitions and energetic materials technology symposium, October 11-14, 2010, Munich, Germany.

[34]D. M. Fox, J. W. Gilman, A. B. Morgan, J. R. Shields, P. H. Maupin, R. E. Lyon, H. C. De Long, P. C. Trulove, Flammability and Thermal Analysis Characterization of ImadazoliumBased Ionic Liquids, Ind. Eng. Chem. Res. 47 (2008) 6327-6332.

[35] J. D. Holbrey, W. M. Reichert, R. P. Swatloski, G. A. Broker, W. R. Pitner, K. R. Seddon, R. D. Rogers, Efficient, halide free synthesis of new, low cost ionic liquids: 1,3dialkylimidazolium salts containing methyl- and ethyl-sulfate anions, Green Chem. 4 (2002) 407-413.

[36] N. Gathergood, P. J. Scammells, M. T. Garcia, Biodegradable ionic liquids: Part III. The first readily biodegradable ionic liquids, Green Chem. 8 (2006) 156-160.

[37] M. J. Earle, J. M. S. S. Esperanca, M. A. Gilea, J. N. Canongia Lopes, L. P. N. Rebelo, J. W. Magee, K. R. Seddon, J. A. Widegren, The distillation and volatility of ionic liquids, Nature. 439 (2006) 831-834. 
[38]P. S. Kulkarni, L. C. Branco, J. G. Crespo, M. C. Nunes, A. Raymundo, C. A. M. Afonso, Comparison of physicochemical properties of new ionic liquids based on imidazolium, quaternary ammonium, and guanidinium cations, Chemistry 13 (2007) 8478-88.

[39] V. Kamavaram, R. G. Reddy, Thermal stabilities of di-alkylimidazolium chloride ionic liquids, Int. J. Therm. Sci. 47 (2008) 773-777.

[40] K. J. Baranyai, G. B. Deacon, D. R. MacFarlane, J. M. Pringle, J. L. Scott, Thermal Degradation of Ionic Liquids at Elevated Temperatures, Aust. J. Chem. 57 (2004) 145-147.

[41]N. Meine, F. Benedito, R. Rinaldi, Thermal stability of ionic liquids assessed by potentiometric titration, Green Chem. 12 (2010) 1711-1714.

[42] T. J. S. Schubert, Ionic liquids as Thermal Fluids - Novel Structural Motifs, Presented at the 1st International Conference on Ionic Liquids in Separation and Purification Technology, Sitges, Spain, 4-7 Sept. 2011.

[43] K. Binnemans, How to select the best ionic liquid for a given application?, Presented at the 1st International Conference on Ionic Liquids in Separation and Purification Technology, Sitges, Spain, 4-7 Sept. 2011.

[44]P. G. Jessop, Searching for green solvents, Green Chem. 13 (2011) 1391-1398.

[45] M. E. M. Berger, D. Assenbaum, N. Taccardi, E. Spiecker, P. Wasserscheid, Simple and recyclable ionic liquid based system for the selective decomposition of formic acid to hydrogen and carbon dioxide. Green Chem. 13 (2011) 1411-1415.

[46] A. E. Visser, R. P. Swatloski, W. M. Reichert, S. T. Griffin, R. D. Rogers, Traditional Extractants in Nontraditional Solvents: Groups 1 and 2 Extraction by Crown Ethers in Room-Temperature Ionic Liquids, Ind. Eng. Chem. 39 (2011) 3596-3604.

[47] S. I. Lall, D. Mancheno, S. Castro, V. Behaj, J. I. Cohen, R. Engel, Polycations. Part X. LIPs, a new category of room temperature ionic liquid based on polyammonium salts, Chem. Commun. (2000) 2413-2414.

[48]L. Gubicza, N. Nemestóthy, T. Fráter, K. Bélafi-Bakó, Enzymatic esterification in ionic liquids integrated with pervaporation for water removal, Green Chem. 5 (2003) 236-239.

[49] C. H. Tseng, J. K. Chang, J. R. Chen, W. T. Tsai, M. J. Deng, I. W. Sun, Corrosion behaviors of materials in aluminum chloride-1-ethyl-3-methylimidazolium chloride ionic liquid, Electrochem. Commun 12 (2010) 1091-1094.

[50]T. Predel, Ionic Liquids as Operating Fluids in High Pressure Applications, Chem. Eng. Technol. 30 (2007) 1475-1480.

[51]T. Predel, E. Schlücker, Ionic Liquids in Oxygen Compression, Chem. Eng. Technol. 32 (2009) 1183-1188.

[52]I Perissi, U. Bardi, S. Caporali, A. Lavacchi, High temperature corrosion properties of ionic liquids, Corros. Sci. 48 (2006) 2349-2362.

[53] A. Brand, T. Hawkins, G. Drake, I. M. K. Ismail, G. Warmoth, L. Hudgens, Energetic Ionic Liquids as TNT Replacements. Presented at the 22nd Safety \& Environmental Protection Subcommittee (SEPS) Joint Meeting, Sandestin Beach, FL, 6-10 Mar 2006. 
[54] J. L. Shamshina, M. Smiglak, D. M. Drab, T. G.Parker, H. W. H. Dykes Jr, R. Di Salvo, A. J. Reich, R. D. Rogers, Catalytic ignition of ionic liquids for propellant applications, Chem. Commun. 46 (2010) 8965-8967.

[55]H. Gao, Y. H. Joo, B. Twamley, Z. Zhou, J. M. Shreeve, Hypergolic ionic liquids with the 2,2-dialkyltriazanium cation, Angew. Chem. Int. Ed. Engl. 48 (2009) 2792-2795.

[56] Y. H. Joo, H. Gao, Y. Zhang, J. M. Shreeve, Inorganic or organic azide-containing hypergolic ionic liquids, Inorg. Chem. 49 (2010) 3282-3288.

[57] Y. Zhang, H. Gao, Y. Guo, Y. H. Joo, J. M. Shreeve, Hypergolic Dimethylhydrazinium Ionic Liquids, Chem. Eur. J. 16 (2010) 3114-3120.

[58]L. He, G. H. Tao, D. A. Parrish, J. M. Shreeve, Nitrocyanamide-based ionic liquids and their potential applications as hypergolic fuels, Chemistry. 16 (2010) 5736-5743.

[59] T. Tsuda, C. L. Hussey. Electrochemical Applications of Room-Temperature Ionic Liquids, J. Electrochem. Soc. 16 (2007) 42-49.

[60]Q. Dong, C. D. Muzny, A. Kazakov, V. Diky, J. W. Magee, J. A. Widegren, R. D. Chirico, K. N. Marsh, M. Frenkel, ILThermo: A Free-Access Web Database for Thermodynamic Properties of Ionic Liquids, J. Chem. Eng. Data. 52 (2011) 1151-1159.

[61] The expert group on quantitative structure-activity relationships (Q)SAR on the principles of validation of (Q)SARs, series on Testing and Assessment No. 49, Organisation for Economic Co-operation and Development (OECD), 2004.

(http://www.oecd.org/officialdocuments/publicdisplaydocumentpdf/?cote=ENV/JM/MONO( 2004)24\&docLanguage $=$ En) (Accessed July 2011).

[62] A. O. Diallo, G. Fayet, C. Len, G Marlair, Evaluation of Heats of Combustion of Ionic Liquids Through Use of Existing and Purpose-Built Models, manuscript submitted to Chem.-Eur. J. for publication, September 26, 2011.

[63]R. N. Walters, R. E. Lyon, Molar Group Contributions to Polymer Flammability, J. App. Polym. Sci. 87 (2002) 548-563.

[64]R. E. Lyon, R. N. Walters, Pyrolysis combustion flow calorimetry, J. Anal. Appl. Pyrolysis 71 (2004) 27-46.

[65]B. Schartel, K. H. Pawlowski, R. E. Lyon, Pyrolysis combustion flow calorimeter: A tool to assess flame retarded PC/ABS materials?, Thermochim. Acta 462 (2007) 1-14.

[66] A. B. Morgan, M. Galaska, Microcombustion calorimetry as a tool for screening flame retardancy in epoxy, Polym. Adv. Technol. 19 (2008) 530-546.

[67]J. M. Cogen, T. S. Lin, R. E. Lyon, Correlations between pyrolysis combustion flow calorimetry and conventional flammability tests with halogen-free flame retardant polyolefin compounds, Fire Mater. 33 (2009) 33-50.

[68]R. E. Lyon, M. T. Takemori, N. Safronava, S. I. Stoliarov, R. N. Walters, A molecular basis for polymer flammability, Polymer 50 (2009), 2608-2617.

[69]P. M. Hergenrother, C. M. Thompson, J. G. Smith, J. W. Connell, J. A. Hinkley, R. E. Lyon, R. Moulton, Flame retardant aircraft epoxy resins containing phosphorus, Polymer 46 (2005) 5012-5024. 


\title{
Revisiting physico-chemical hazards of ionic liquids
}

\author{
Alpha O. Diallo, ${ }^{\text {a,b }}$ Christophe Len, ${ }^{\mathrm{b}}$ Alexander B. Morgan, ${ }^{\mathrm{c}}$ Guy Marlair ${ }^{* a}$ \\ ${ }^{a}$ Institut National de l'Environnement Industriel et des Risques (INERIS), Parc Technologique \\ Alata, BP2, 60550, Verneuil-en-Halatte, France \\ ${ }^{b}$ UTC - ESCOM, EA 4297, Transformations Intégrées de la Matière Renouvelable, Centre de \\ Recherches de Royallieu, BP 20529, F-60205 Compiègne Cedex, France \\ c University of Dayton Research Institute (UDRI) - Multiscale Composites and Polymers \\ Division 300 College Park, Dayton, Ohio 45469-0160, USA
}

\begin{abstract}
This paper is a consolidated overview of what was originally presented by the co-authors at the ILSEPT 2011 conference regarding physico-chemical safety issues pertaining to ionic liquids (ILs). Indeed safety performance of ILs relating to physico-chemical hazards is very rarely investigated as it is often perceived as a non existing issue due to the lack of traditional flashpoint for these liquids. The paper outlines: a) why it is justified to have a detailed look of physicochemical properties of ILs in the context of separation and purification technologies, b) sort out misleading from true general statements regarding actual safety, c) discuss physico-chemical hazard rating systems and their limitation in the context of overall risk evaluation, and d) report on the early findings of a joint initiative regarding the development of predictive tools for heats of combustion for ILs and experimental results obtained by use of the pyrolysis combustion flow calorimetry (PCFC) on the effective rate of heat release from ILs in fire conditions. Finally, perspectives regarding future work with regard to better knowledge and assessment of ILs physico-chemical related issues are given with the aim of serving sustainable design and use of ILs.
\end{abstract}

Keywords: Ionic liquids, physico-chemical hazards, heats of combustion, prediction models, rates of heat release 


\section{Introduction}

The wide range of potential combinations of cations and anions to yield ILs $\left(10^{18}\right.$ possibilities see Figure 1) allows for a great variety of interactions and applications due to the tunable properties of the ILs. This is why ILs are designated as designer solvents as they are finally tunable to obtain desirable functionalities. However, by contrast the quasi-infinite number of potential ILs should work as a warning signal that safety advantages are perhaps claimed in a too much generic manner in terms of low vapor pressure (if not involatility), very good thermal stability, and absence of flammability property. Specifically, claims of ILs being "nonflammable" are hardly ever reported in appropriate context. Non-flammable carries specific meaning in fire safety circles, and as we will show, one cannot claim these materials to be nonflammable even if they have no specific flashpoint by traditional solvent flammability tests.

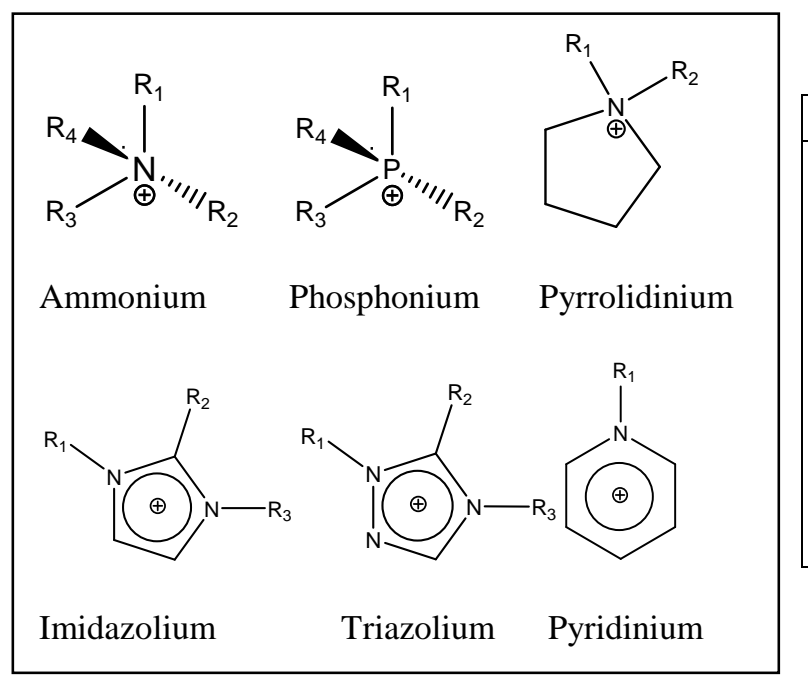

\begin{tabular}{|l|l|}
\hline Inorganic anions & Organic anions \\
\hline $\mathrm{F}^{-}, \mathrm{Cl}^{-}, \mathrm{Br}^{-}, \mathrm{I}^{-}$ & $\mathrm{CH}_{3} \mathrm{CO}_{2}^{-}, \quad \mathrm{CH}_{3} \mathrm{SO}_{4}^{-}$, \\
$\mathrm{BF}_{4}^{-}, \mathrm{PF}_{6}^{-}, \mathrm{SbF}_{6}^{-}, \mathrm{AsF}_{6}^{-}$ & $\mathrm{C}_{6} \mathrm{H}_{5} \mathrm{SO}_{3}^{-}(=\mathrm{OTs})$ \\
$\mathrm{NO}_{3}^{-}, \mathrm{ClO}_{4}^{-}$ & $\mathrm{CF}_{3} \mathrm{CO}_{2}^{-}, \mathrm{C}\left(\mathrm{CF}_{3} \mathrm{SO}_{2}\right)_{3}^{-}$ \\
$\mathrm{Al}_{\mathrm{x}} \mathrm{Cl}_{(3 \mathrm{x}+1)}^{-}$, & $\mathrm{CF}_{3} \mathrm{SO}_{3}^{-}(=\mathrm{OTf})$ \\
$\mathrm{Al}_{\mathrm{x}} \mathrm{Et}_{\mathrm{x}} \mathrm{Cl}_{(2 \mathrm{x}+1)}^{-}$, & $\mathrm{N}^{-} \mathrm{SO}_{2} \mathrm{CF}_{3)_{2}}^{-}\left(=\mathrm{NTf}_{2}\right)$ \\
$\mathrm{CuCl}_{2}^{-}, \mathrm{AuCl}_{4}^{-}, \mathrm{ZnCl}_{3}^{-}$, & $\mathrm{BR}_{4}^{-}, \mathrm{R}_{3} \mathrm{BOH}^{-}$ \\
$\mathrm{SnCl}_{3}^{-}$ & \\
\hline
\end{tabular}

Figure 1. Chemical structures of some major key ionic liquids (left hand side: cations; right end side: anions)

A second warning signal towards the need of careful examination of potential safety hazards arises from the observation of the chemical diversity of ILs main families, as illustrated by Figure 1.This paper covers a discussion on these issues, focusing only on physico-chemical hazards by means of an analytic review of existing but dispersed information and first results of original work performed by the contributing team. 


\section{Sorting out myths from reality with ionic liquids phys-chem. hazards}

The growing interest in both industrial and academic research on ILs, particularly in separation and purification technologies where nearly all families of ILs are concerned, has been done with the generic assumption that these chemicals are implicitly highly stable, non flammable, or safe to use in any process [1-3].Not arguing against the fact that ILs, as a trend, present superior fire safety margins compared to conventional highly flammable solvents,_INERIS and co-workers have identified that the evaluation of physico-chemical risks was deserving more attention for a number of reasons:

a) Open literature and commercial leaflets still contain misleading information on ILs in reporting too generally (or incorrectly) on volatility, flammability behaviours, and thermal stability.

b) The European Community Regulation on chemicals and their safe use, dealing with the Registration, Evaluation, Authorisation and Restriction of Chemical substances (REACH) [4] and the Classification Labelling and Packaging regulation (CLP) [5], demand more in-depth analysis of physico-chemical risk evaluation.

c) First order evaluation of physico-chemical properties in relation with safety are needed in early stages of ILs design

d) ILs are known to thermally decompose at varying temperature, which, like in case of polymers, requires other measurements than flash point to assess flammability

When considering a $1^{\text {st }}$ order evaluation of hazards pertaining to ILs, and partly linked with what has been said above is the use of inappropriate wording in describing the properties of ILs, Table 1 mention those wrong ways to report of hazards of ILs with in the right column a more consistent manner and correct wording to deal with same aspect. 
Table 1. Misleading and more correct statements about ionic liquids safety properties

\begin{tabular}{|c|c|}
\hline Inappropriate wording & More correct wording \\
\hline $\begin{array}{l}\text { Non-flammable, Inflammable, } \\
\text { Non combustible }\end{array}$ & $\begin{array}{l}\text { - either: "not capable of burning with flames" (as would say a } \\
\text { dictionary in a generic manner, if true) } \\
\text { - Or not flammable (as a liquid) according to criteria of the } \\
\text { Globally Harmonized System (GHS) or CLP regulation (or } \\
\text { other hazard material regulation) } \\
\text { - Good reaction to fire performance combustion tests, but could } \\
\text { combust in other higher heat combustion tests. }\end{array}$ \\
\hline Non volatility, Involatility & - Usually low to very low volatility \\
\hline Extremely high thermal stability & $\begin{array}{l}\text { - Rather good to very good thermal stability properties relative } \\
\text { to other similar materials (however highly depending of a case } \\
\text { by case analysis - one cannot compare organic liquids to } \\
\text { glasses or ceramics obviously from a thermal stability } \\
\text { perspective) }\end{array}$ \\
\hline $\begin{array}{l}\text { ILs act as corrosion inhibitors to } \\
\text { metals }\end{array}$ & $\begin{array}{l}\text { - Due to chemical structure properties, many ILs present } \\
\text { corrosion to metal potential. } \\
\text { - Some may be considered by convention "non corrosive to } \\
\text { metals" according to GHS or CLP criteria } \\
\text { - Others are to be classified as "corrosive to metals" by } \\
\text { convention according to the same regulatory context }\end{array}$ \\
\hline
\end{tabular}

Notwithstanding above mentioned shortcomings about the way safety issues regarding ILs were assessed in the past and sometimes still are, the trend towards some progress has appeared in recent open literature. As a proof of this, a few early studies have been devoted to actually qualify physico-chemical hazards in dedicated and consistent way for some ILs [6-9]. As an outcome of those early studies, not all ILs can be considered intrinsically safe and some may trigger physicochemical risks during their synthesis. Indeed, in a lot of synthesis routes halogen atoms are involved which can lead to corrosion issues.

Recent papers have in particular helped to fight against the commonly reported non volatility and extreme thermal stability of ILs. As an example, Earle's study [10] showed that many ILs, particularly imidazolium-based ILs can be distilled (under partial vacuum) and their decomposition products are usually found to be volatile. Other researchers have addressed experimentally thermal stability properties of a number of ILs, showing that thermal stability up to $400^{\circ} \mathrm{C}$ or more is not the common rule for ILs and that in reality, thermal stability may vary 
greatly [11-14]. Some speakers at the ILSPET 2011 conference also pointed out that for some applications some ILs are not an option due to thermal stability issues $[15,16]$.

Beyond the issue of intrinsic physico-chemical potential issues of ILs, it is clear that "green solvent" character of ILs has to be appraised on the life cycle analysis. In doing such an analysis, processing some ILs may be regarded - to some extent - at least more complex if not finally less green for environmental or for safety reasons as compared to conventional solvents. Jessop [17] has shown this via a $1^{\text {st }}$ order indicator by considering the number of elemental process steps that are needed to produce ILs as compared to conventional flammable solvents.

\section{Conventional vs. real life hazard assessment}

\subsection{Regulatory schemes for hazards classification}

Recently, changes have been made in chemicals hazards classification in the European Union. At the international level, the United Nations (UN) has developed the so called GHS system, aiming at harmonizing classification of hazardous materials at a worldwide level. The application of CLP in the EU implies, in the case of physical hazard, the transposition from the 5 categories of hazards in the old European classification system (67/548/EEC) to newly established 16 classes of hazards originating from the GHS. Some categories of hazards are modified - through modified criteria or new method for testing - and new classes of hazards have appeared, as illustrated in Figure 2. Thus, the regulatory environment for risk control involves at least a new rigor in the identification of "conventional" physico-chemical hazards. A real thorough assessment of physico-chemical hazards that may involve the use of ILs should reflect these new changes and requires a detailed analysis, owing to great variety of ILs chemical structures and taking account of the degree of relevance of classes of hazards for ILs. Even the initial physical state of ILs (that needs to take account of ambient or sub-ambient temperature conditions) must be considered as all ILs are not liquid at room temperature or quickly solidify just below room temperature. 


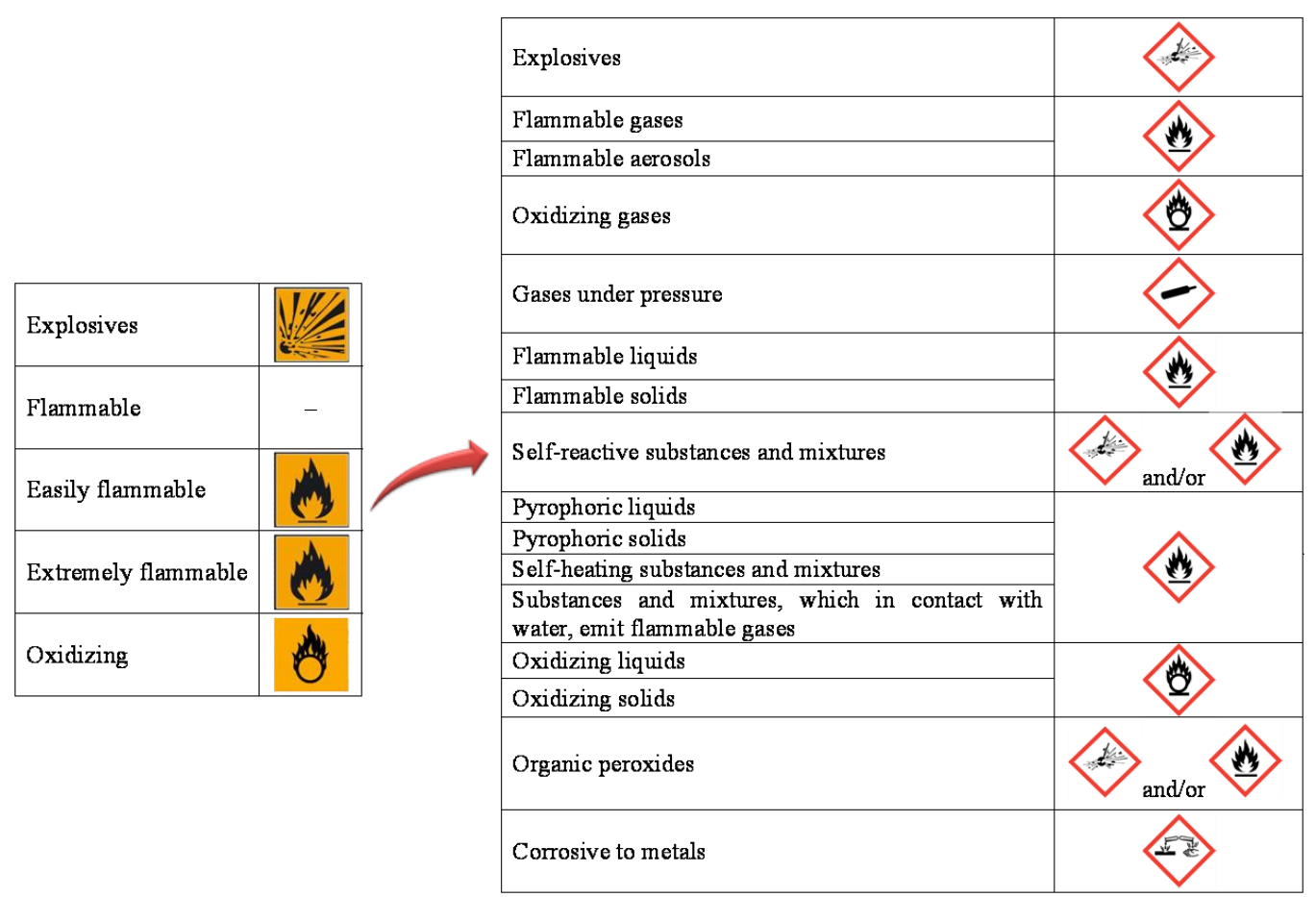

Figure 2. Recent regulatory move in physico-chemical hazards classification from 5 categories of hazard to 16 classes of hazard described, as implied in the CLP (from ref. 18)

\subsection{Limitations of hazard classification systems}

Conventional hazards are needed to define physico-chemical hazards properties from a regulatory viewpoint, but there are important limitations of using these methods because:

a) conventions are changing versus time (e.g. CLP versus Substance Directive 67/548/EEC),

b) conventions are not the same in all countries,

c) conventions provide a simplified view of the actual hazards which is a limitation per se if considered too abruptly.

For insistence, the flashpoints are not defined the same way in the CLP regulations and in the US Occupational Safety and Health Administration (OSHA) regulations. Actual hazard profiles are different to the conventional hazards in so far as "non-flammable" products (from a regulatory viewpoint) may however trigger a fire or an explosion risk depending on environmental conditions of material processing, use or storage conditions (atmosphere, heat, ignition sources, etc.). Another example of limitation in conventional hazard rating lies in the procedure applying for the metal corrosion ability of a material. Corrosivity to metal is indeed a new property taken in consideration in the CLP system. Conventional "corrosive to metals property" as defined in 
GHS (2002) and CLP (2009) stands for substances or mixtures which by chemical action will materially damage or even destroy metals, but criteria are only fixed for uniform and pitting corrosion on steel and aluminium, which inherently contain a double limitation in terms of metal portfolio under consideration and also as regard the corrosion process. Some ILs are likely to be corrosive to other metals although they are "non corrosive" to steel and aluminium [19-26]. Additionally, some ILs may be corrosive to metals and ceramics, especially those containing fluoride in their structure. Last, but not least, incompatibilities between chemicals are not within the scope of hazards materials classification regulations, but they shall not be ignored in the hazard assessment of physico-chemical properties of ILs. The more trivial example of that is the hydrophobicity of some ILs (not a generic rule) but some of the anions are highly acidic were they to be protonated which could lead to some oxidizer-type chemical reactions at elevated temperature.

\subsection{Lessons from incidents and recent safety-oriented research}

Although these materials have been labelled or described as "not flammable", some ILs have been observed burning with flames accidentally in laboratories, moreover, self sustained or piloted combustion of some ILs have been shown as a potential incidental scenario in some experiments. In most cases, rapid exothermic decomposition occurs when ILs with high nitrogen content are taken to high temperature and the subsequent decomposition products are sensitive to ignition and combustion. The combustion may even tend to be explosive even under vacuum as shown by Smiglak [6] for imidazolium-based ILs or hydrazinium-based ILs tested in their works. In addition, burning tests performed on 4-Amino-1-methyl-1,2,4-triazolium nitrate by Schaller [8] have led to flame temperature of 2,200 K. In some cases ILs are even combustible by design where intended for use as propellants as alternatives to hydrazine [27,28]. Ultimately, once the various molecular bonds reach their thermal decomposition temperature in these carbonbased ILs, any number of flammable small molecules could be release leading to combustion. These examples show again that the traditional flashpoint type tests are certainly not enough to properly characterize the fire hazard.

Flammability issues may also arise from specific behaviour of hypergolic ILs in which in contact with the dinitrogen tetroxide $\left(\mathrm{N}_{2} \mathrm{O}_{4}\right)$ or white fuming nitric acid (WFNA) can spontaneously ignite due to the highly exothermic reaction that takes place. It was shown that ILs with the dicyanamide or nitrocyanamide anion in particular are hypergolic [29-32]. Also, 2,2- 
dimethyltriazanium nitrate and 2,2-dimethyltriazanium chloride are hypergolic prone materials [29], suggesting that also the nature of the cation of the IL can modify hypergolic properties.

Many different processes using ILs may lead to metal corrosion. Indeed many papers have reported the instability of ILs contained $\mathrm{PF}_{6}{ }^{-}$anion towards hydrolysis in contact with moisture, forming volatiles compounds including $\mathrm{HF}$ and $\mathrm{POF}_{3}$ which are known to damage materials such as steel and glass [19-22].

Tseng [23] recently showed excellent resistance to corrosion of stainless steel 304SS against chloride-1-ethyl-3-methylimidazolium chloride, whereas same IL severely corrodes titanium.

In his researches about the use of ILs in high pressure applications, Predel [24,25] observed that even when all of the tested ILs showed very low corrosiveness to stainless steel, the corrosion rates of some ILs to steel and cupriferous materials were too high. He concluded that many ILs are definitely not suitable in an application where copper is involved.

The effect of temperature on corrosion properties of 1-butyl-3-methyl-imidazolium bis(trifluoromethanesulfonyl)imide has also been studied by Perissi [26] who has shown that an increase in temperature may lead to corrosion of several metals and metal alloys (copper, nickel, AISI 1018 steel, brass, Inconel 600).

The corrosivity for a given metal is determined by the chemical structure of the IL cation and the nature of the anion. The results obtained indicate that materials selection for technical equipment used in IL-based chemical processes is a very important issue and requires further investigations with respect to chemical and electrochemical corrosion mechanisms and its relation to the chemical structure and concentration of ILs.

The impurity levels of ILs are also issues that have to be taken in account because they considerably affect both the physico-chemical and electrochemical properties of ILs. Tetsuya [33] showed that the addition of water to 1-ethyl-3methylimidazolium chloride results in a violent reaction with the evolution of heat and $\mathrm{HCl}$ gas and an obvious change in the appearance of the IL. In his work, Smiglak [6] suspected that impurities in the trihexyltetradecylphosphonium chloride are responsible for ignition spray even as this IL was said to be stable over $300^{\circ} \mathrm{C}$.

In view of all these findings, and although so far no major accident has been reported with ILs at the current stages of use, it seems pertinent to develop systematic and comprehensive 
methodologies of determining hazardous profiles of ILs. Thus, focus on the development of reliable simple methods for predicting heats of complete combustion of ILs has been done as a starting point for a more comprehensive consideration of safe use of ILs in the context of green chemistry and biorefining.

\section{New development and early findings dealing with the fire hazard}

\subsection{Prediction of heats of combustion}

Complete heat of combustion is one of the first indicators used to pre-assess potential fire hazards of a chemical substance. It represents the overall energy content that a substance is liable to release by complete combustion in a fire event.

For that purpose, an overview of 18 existing empirical correlations giving heats of combustion developed in early times of combustion science has been performed and re-examined in a scientific-sound manner for their ability to predict heats of combustion of ILs. These models were based on structure-property relationships, in which structure was simply described by elemental mass composition descriptors and related models obtained from multilinear regression techniques. As those 18 empirical correlations have clearly been established and validated against products data excluding the case of ILs, we have compiled thermodynamic data of some 53 ILs covering 8 families of most common ILs in a new database that has served as validation sets. Per se, such an exercise was not trivial and showed us the extreme difficulty to access thermodynamic data in the open literature. For example, in the IUPAC Ionic Liquids Database website [34], there are no data at all available for heats of combustion of ILs. On that purpose, 18 correlations [35-39] have been tested using the entire database of ILs, those models are given in Table 2. 
Table 2. Survey of early published correlations developed to predict heats of combustion (Note: (i) HHV is higher heating value, (ii) LHV is lower heating value, (iii) HHV and LHV are expressed in $\mathrm{MJ} / \mathrm{kg}$ ).

\begin{tabular}{|c|c|c|}
\hline Name investigator & Atoms & Formula of heats of combustion \\
\hline $\operatorname{Beckman}(1990)^{[34]}$ & $\mathrm{C}, \mathrm{H}, \mathrm{O}, \mathrm{S}$ & $H H V=35.20 \cdot C+94.40 \cdot H-10.50 \cdot(S-O)$ \\
\hline Boie $(1953)^{[34,35]}$ & $\begin{array}{l}\mathrm{C}, \mathrm{H}, \mathrm{O}, \mathrm{N}, \\
\mathrm{S}\end{array}$ & $H H V=35.17 \cdot C+116.26 \cdot H-11.10 \cdot O+6.28 \cdot N+10.47 \cdot S$ \\
\hline D'Huart $(1930)^{[34,35]}$ & $\mathrm{C}, \mathrm{H}, \mathrm{O}, \mathrm{S}$ & $H H V=33.91 \cdot C+143.37 \cdot H-12.73 \cdot O+9.31 \cdot S$ \\
\hline Dulong $^{[34,35]}$ & $\mathrm{C}, \mathrm{H}, \mathrm{O}, \mathrm{S}$ & $H H V=33.83 \cdot C+144.3 \cdot\left(H-\frac{O}{8}\right)+9.42 \cdot S$ \\
\hline Dulong-Berthelot ${ }^{[34]}$ & $\begin{array}{l}\mathrm{C}, \mathrm{H}, \mathrm{O}, \mathrm{N}, \\
\mathrm{S}\end{array}$ & $H H V=34.14 \cdot C+144.45 \cdot H-\frac{N+O-1}{8}+9.30 \cdot S$ \\
\hline Garvin $(1998)^{[35]}$ & $\begin{array}{l}\mathrm{C}, \mathrm{H}, \mathrm{O}, \mathrm{N}, \\
\mathrm{S}, \mathrm{Cl}, \mathrm{F} \\
\mathrm{Br}, \mathrm{I}\end{array}$ & $\begin{aligned} L H V= & 36.2 \cdot C+90.0 \cdot H-10.6 O+8.0 \cdot N+10.6 \cdot S \\
& -2.05 \cdot C l-3.5 \cdot F-0.16 \cdot B r+0.26 \cdot I\end{aligned}$ \\
\hline Grumell-Davies $(1933)^{[34]}$ & $\mathrm{C}, \mathrm{H}, \mathrm{O}, \mathrm{S}$ & $H H V=(1.52 \cdot H+98.75)\left(\frac{C}{3}+H-\frac{O-S}{8}\right)$ \\
\hline $\operatorname{Gumz}(1938)^{[34,35]}$ & $\begin{array}{l}\mathrm{C}, \mathrm{H}, \mathrm{O} \mathrm{N}, \\
\mathrm{S}\end{array}$ & $H H V=34.03 \cdot C+124.32 \cdot H-9.84 \cdot O+6.28 \cdot N+19.09 \cdot S$ \\
\hline Hshieh $(1999)^{[36]}$ & $\begin{array}{l}\mathrm{C}, \mathrm{H}, \mathrm{O}, \mathrm{N}, \\
\mathrm{S}, \mathrm{Cl}, \mathrm{Si} \\
\mathrm{Br}, \mathrm{I}\end{array}$ & $\begin{aligned} H H V= & 34.92 \cdot C+120.68 \cdot H-18.15 \cdot O+2.84 \cdot N+7.98 \cdot S \\
& -3.56 \cdot C l+28.43 \cdot S i-1.10 \cdot B r+0.11 \cdot I\end{aligned}$ \\
\hline Hshieh $(2003)^{[37]}$ & $\begin{array}{l}\mathrm{C}, \mathrm{H}, \mathrm{O}, \mathrm{N} \\
\mathrm{S}, \mathrm{Cl}, \mathrm{F}\end{array}$ & $\begin{aligned} H H V= & 34.68 \cdot C+103.82 \cdot H-6.64 \cdot O+1.45 \cdot N+13.12 \cdot S \\
& -0.66 \cdot C l-2.37 \cdot F\end{aligned}$ \\
\hline Lloyd-Davenport (1980) ${ }^{[38]}$ & $\begin{array}{l}\mathrm{C}, \mathrm{H}, \mathrm{O}, \mathrm{N}, \\
\mathrm{S}\end{array}$ & $H H V=35.78 \cdot C+113.57 \cdot H-8.45 \cdot O+5.90 \cdot N+11.19 \cdot S$ \\
\hline Mott-Spooner $(1940)^{[34,35]}$ & $\mathrm{C}, \mathrm{H}, \mathrm{O}, \mathrm{S}$ & $\begin{array}{l}H H V=33.61 \cdot C+141.90 \cdot H-14.53 \cdot O+9.42 \cdot S(\text { if } O \leq 15 \%) \\
H H V=33.61 \cdot C+141.90 \cdot H-(15.32-0.07 \cdot O) \cdot O+9.42 \cdot S(\text { if } O>15 \%)\end{array}$ \\
\hline Patary $^{[35]}$ & $\mathrm{C}, \mathrm{H}, \mathrm{O}, \mathrm{S}$ & $H H V=35.58 \cdot C+113.00 \cdot H-11.30 \cdot O+10.46 \cdot S$ \\
\hline Steuer $(1926)^{[34]}$ & $\mathrm{C}, \mathrm{H}, \mathrm{O}, \mathrm{S}$ & $H H V=33.91\left(C-\frac{3}{8} \cdot O\right)+23.86 \cdot\left(\frac{3}{8} \cdot O\right)+144.40 \cdot\left(H-\frac{O}{16}\right)+10.47 \cdot S$ \\
\hline Strache-Lant $(1924)^{[35]}$ & $\mathrm{C}, \mathrm{H}, \mathrm{O}, \mathrm{S}$ & $H H V=34.06 \cdot C+143.24 \cdot H-15.32 \cdot O+10.47 \cdot S$ \\
\hline Sumegi $(1939)^{[34]}$ & $\mathrm{C}, \mathrm{H}, \mathrm{O}, \mathrm{S}$ & $H H V=33.91 \cdot\left(C-0.75 \cdot \frac{O}{2}\right)+144.40 \cdot\left(H-0.125 \cdot \frac{O}{2}\right)+10.47 \cdot S$ \\
\hline Vondracek $(1978)^{[34,35]}$ & $\mathrm{C}, \mathrm{H}, \mathrm{O}, \mathrm{S}$ & $H H V=(37.30-0.026 \cdot C) \cdot C+144.40 \cdot\left(H-\frac{O}{10}\right)+10.47 \cdot S$ \\
\hline
\end{tabular}

From the examination of the 18 correlations, 5 of those were revealed to be quite effective for predicting reasonable heats of combustion of ILs $\left(\mathrm{R}^{2}>0.94\right)$. Performances of the 5 best models are described in Table 3. Moreover, the database was also used to develop a fully-dedicated model according to the OECD principles for regulatory acceptability [40], which expressly requires an external validation process. 
The same database compiling measured heats of combustion of 53 ILs was used this time differently by splitting the data into a training set (to establish parameters of the new model with same descriptors as those of the previously 18 correlation examined) and a validation set. This work has been detailed in the work performed by Diallo et al. [41].

Not surprisingly, the new model works even slightly better and opens the route for addressing brand new ILs that would require special focus.

Table 3. Predictive powers of the top 5 existing models [41]

\begin{tabular}{|llcc|}
\hline No & Correlation & \% error & $\mathrm{R}^{2}$ \\
\hline \hline 1 & Boie & 4.6 & 0.97 \\
2 & Dulong-Berthelot & 6.4 & 0.94 \\
3 & Garvin & 4.9 & 0.96 \\
4 & Gumz & 4.1 & 0.97 \\
5 & Lloyd-Davenport & 3.2 & 0.98 \\
\hline
\end{tabular}

Figure 3 plots predicted values of heats of combustion from ILs in our database, grouped by family of ILs, showing how far heats of combustion may vary. As an example, in the case of imidazolium-based ILs, the heats of combustion vary quite significantly from some $15 \mathrm{MJ} / \mathrm{kg}$ up to $35 \mathrm{MJ} / \mathrm{kg}$. This finding suggests complete combustion of some ILs is found comparable to those pertaining to many usual combustible or flammable materials. 


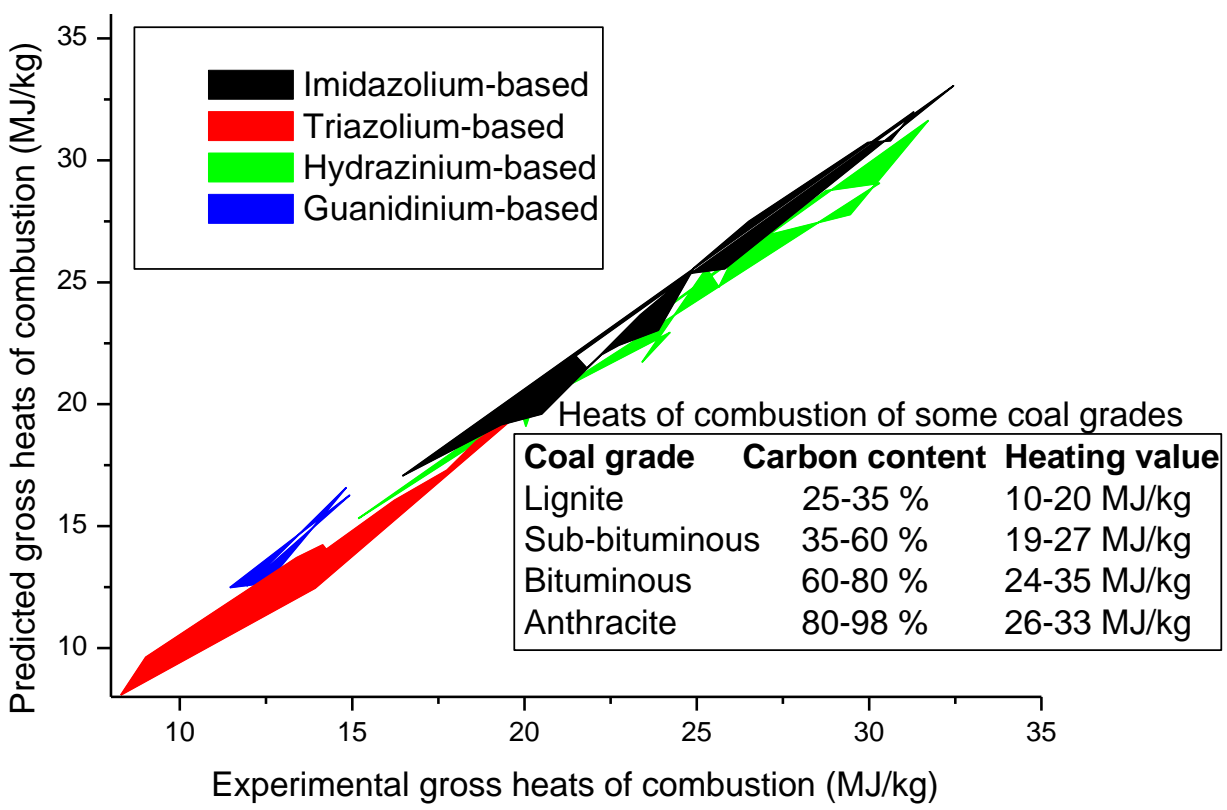

Figure 3. Predicted vs. reported gross heats of combustion for ionic liquids based on the dedicated-model (adapted from ref. [41])

In Table 4, the model predictability has been use to pre-assess combustibility property of ILs not present in our database. As can be seen, the values of heats of combustion expand even larger, showing for some of them, values far exceeding the upper limit of ILs that were originally in our database. In particular, phosphonium-based ILs looks potentially very energetic which claim from further assessment of effective rates of heat release that can only be obtained by experiments. 
Table 4. Predictability of heats of combustion of some ILs using the purpose-built model (from ref. [41])

\begin{tabular}{|c|c|c|c|}
\hline Chemical Name & Synonym & Formula & $\begin{array}{l}\text { Predicted values of heats } \\
\text { of combustion }(\mathrm{MJ} / \mathrm{kg})\end{array}$ \\
\hline 1-ethyl-3-methylimidazolium bromide & emim $\mathrm{Br}$ & $\mathrm{C}_{6} \mathrm{H}_{11} \mathrm{BrN}_{2}$ & 20,2 \\
\hline $\begin{array}{l}\text { 1-ethyl-3-methylimidazolium } \\
\text { trifluoromethanesulfonate }\end{array}$ & emim otf & $\mathrm{C}_{7} \mathrm{H}_{11} \mathrm{~F}_{3} \mathrm{~N}_{2} \mathrm{O}_{3} \mathrm{~S}$ & 15,3 \\
\hline 1-ethyl-3-methylimidazolium acetate & emim ac & $\mathrm{C}_{8} \mathrm{H}_{14} \mathrm{~N}_{2} \mathrm{O}_{2}$ & 29,6 \\
\hline $\begin{array}{l}\text { 1-butyl-3-methylimidazolium } \\
\text { hexafluorophosphate }\end{array}$ & bmim PF6 & $\mathrm{C}_{8} \mathrm{H}_{15} \mathrm{~F}_{6} \mathrm{~N}_{2} \mathrm{P}$ & 17,8 \\
\hline N-butylpyridinium tetrafluoroborate & bpyr BF4 & $\mathrm{C}_{9} \mathrm{H}_{14} \mathrm{BF}_{4} \mathrm{~N}$ & 24,1 \\
\hline $\begin{array}{l}\text { 1-butyl-3-methylimidazolium } \\
\text { bis(trifluoromethylsulfonyl)amide }\end{array}$ & bmim ntf & $\mathrm{C}_{10} \mathrm{H}_{15} \mathrm{~F}_{6} \mathrm{~N}_{3} \mathrm{O}_{4} \mathrm{~S}_{2}$ & 13,2 \\
\hline $\begin{array}{l}\text { N-butyl-N-methylpyrrolidinium } \\
\text { trifluoromethanesulfonate }\end{array}$ & bmpl otf & $\mathrm{C}_{10} \mathrm{H}_{20} \mathrm{~F}_{3} \mathrm{NO}_{3} \mathrm{~S}$ & 21,7 \\
\hline $\begin{array}{l}\text { 1-butyl-2,3-dimethylimidazolium } \\
\text { bis(trifluoromethylsulfonyl)amide }\end{array}$ & bmmim ntf & $\mathrm{C}_{11} \mathrm{H}_{17} \mathrm{~F}_{6} \mathrm{~N}_{3} \mathrm{O}_{4} \mathrm{~S}_{2}$ & 14,3 \\
\hline $\begin{array}{l}\text { 1-hexyl-3-methylimidazolium } \\
\text { trifluoromethanesulfonate }\end{array}$ & hmim otf & $\mathrm{C}_{11} \mathrm{H}_{19} \mathrm{~F}_{3} \mathrm{~N}_{2} \mathrm{O}_{3} \mathrm{~S}$ & 21,0 \\
\hline N-butyl-N-methylpyrrolidinium dicyanamide & bmpl dca & $\mathrm{C}_{11} \mathrm{H}_{20} \mathrm{~N}_{4}$ & 35,2 \\
\hline tributylethylphosphonium diethylphosphate & P2444 dep & $\mathrm{C}_{18} \mathrm{H}_{42} \mathrm{O}_{4} \mathrm{P}_{2}$ & 32,2 \\
\hline $\begin{array}{l}\text { triisobutyl(methyl)phosphonium p- } \\
\text { toluenesulfonate }\end{array}$ & $\mathrm{P}(\mathrm{ib})(\mathrm{ib})(\mathrm{ib}) 1$ tos & $\mathrm{C}_{20} \mathrm{H}_{37} \mathrm{O}_{3} \mathrm{PS}$ & 32,4 \\
\hline trihexyl(tetradecyl)phosphonium chloride & $\mathrm{P} 666(14) \mathrm{Cl}$ & $\mathrm{C}_{32} \mathrm{H}_{68} \mathrm{ClP}$ & 42,2 \\
\hline trihexyl(tetradecyl)phosphonium bromide & $\mathrm{P} 666(14) \mathrm{Br}$ & $\mathrm{C}_{32} \mathrm{H}_{68} \mathrm{BrP}$ & 38,5 \\
\hline trihexyl(tetradecyl)phosphonium dicyanamide & P666(14) dca & $\mathrm{C}_{34} \mathrm{H}_{68} \mathrm{~N}_{3} \mathrm{P}$ & 41,6 \\
\hline
\end{tabular}

\subsection{Early findings on rates of heat releases}

In 2008, studies were conducted to assess the heat release of ILs via pyrolysis combustion flow calorimetry (PCFC), which is a small scale oxygen consumption calorimetry test [9]. This was done because at the time, the ILs were all shown to have no flashpoint, and yet from a physicochemical perspective, it was clear that these salts did have chemical structures capable of releasing heat if they were thermally decomposed and exposed to oxidizing conditions. Therefore some quick assessment of ILs was conducted, using the PCFC method to quantify heat release in relation to the chemical structure of the IL.

The PCFC is a standard method (ASTM D7309) for measuring the heat release via oxygen consumption calorimetry at the 5-50mg sample size, making it a potent technique for quantification of material flammability without consuming large amounts of material. According to this standard, two methods A and B can be used for the measurement of the heat release, according to mode of combustion targeted. This technique has been shown to quantify the heat 
release for a wide range of solids (i.e. - materials without an obvious flashpoint) [42-48] and therefore was thought to be a relevant test to measure the heat release of ILs at microscale. Indeed, with the PCFC, one can obtain fundamental heat release data for a material as a function of its chemical structure, and can study heat release rates versus temperature, as well as actual heat of combustion behaviour. Results from early burn tests regarding imidazolium based ILs, using Method B of ASTM D7309 [49] are shown in Table 5. For comparison, predicted values of same ILs making use of our purpose-built model are given in last column in same table.

Table 5. Actual heat of combustion data for ILs tested with the PCFC (adapted from Morgan's work [49]) compared to predicted values of HHVs given by the purposed-build model [41]

\begin{tabular}{|lcccc|}
\hline Sample & $\begin{array}{c}\text { Char Yield } \\
(\mathrm{wt} \%)\end{array}$ & $\begin{array}{c}\text { HRR Peak(s) } \\
(\mathrm{W} / \mathrm{g})\end{array}$ & $\begin{array}{c}\text { Total HR } \\
(\mathrm{kJ} / \mathrm{g})\end{array}$ & $\begin{array}{c}\text { Predicted HHV } \\
(\mathrm{kJ} / \mathrm{g})\end{array}$ \\
\hline \hline 1-butyl-3-methylimidazolium tetrafluoroborate & 0.29 & $306-194$ & 27.7 & 22.9 \\
1-butyl-2,3-dimethylimidazolium tetrafluoroborate & 1.08 & $381-327$ & 22.6 & 25.6 \\
1-butyl-3-methylimidazolium hexafluorophosphate & 1.41 & $333-149$ & 15.1 & 17.8 \\
$\begin{array}{l}\text { 1-butyl-2,3-dimethylimidazolium } \\
\text { bis(trifluoromethylsulfonyl)amide (TFSI) }\end{array}$ & 2.29 & $209-111$ & 11.4 & 14.3 \\
$\begin{array}{l}\text { 1-butyl-2,3-dimethylimidazolium dicyanamide } \\
\text { (N(CN)2) }\end{array}$ & 3.82 & $371-341$ & 17.6 & 31.9 \\
1-hexadecyl-2,3-dimethylimidazolium chloride & 0.00 & 1638 & 34.2 & 40.8 \\
1-hexadecyl-2,3-dimethylimidazolium bromide & 0.72 & $727-580$ & 27.4 & 35.6 \\
1-hexadecyl-2,3-dimethylimidazolium & 12.70 & 594 & 20.5 & 30.2 \\
hexafluorophosphate & 0.14 & 753 & 26.6 & 32.0 \\
1-butyl-2,3-dimethylimidazolium chloride & 0.00 & 344 & 17.3 & 25.1 \\
$\begin{array}{l}\text { 1-butyl-2,3-dimethylimidazolium bromide } \\
\text { 1-butyl-2,3-dimethylimidazolium }\end{array}$ & 6.60 & 403 & 15.1 & 19.2 \\
hexafluorophosphate & & &
\end{tabular}

From this study, there are several useful conclusions that could be made. In general, the more carbon in the ILs structure, the more heat release generated by the material when it burned. Further, counterion had a definite effect on flammability, with the general trend of $\mathrm{Cl}<\mathrm{Br}<\mathrm{N}(\mathrm{CN})_{2}<\mathrm{BF}_{4}=\mathrm{PF}_{6}<\mathrm{TFSI}$ when looking at which counterion reduced heat release the most. One could argue that some of the counterions not only reduce the fuel available for combustion through char formation, but they also may be capable of unusual gas phase reactions which inhibit combustion and oxygen consumption. Indeed, up to $800^{\circ} \mathrm{C}$, many materials left behind thermally stable char under the oxidative conditions of the test.

Along with the measured total heat release (which under ASTM D7309, Method B is equal to heat of combustion), heat release rate peak values were studied. Some of the ILs yielded simple 
single peak/event decompositions and heat release, while others were more complex. Again the counterion changed the condensed phase decomposition of the material. A dramatic example of this would be comparing the $\mathrm{DMBI}-\mathrm{BF}_{4}$ to the $\mathrm{DMBI}-\mathrm{Cl}$ which show greatly different heat release profiles. So with the PCFC, one can measure the heats of combustion of liquids that have no flashpoint while also studying their heat release/decomposition profiles which are affected by chemical structure.

While the PCFC showed some useful insight into the flammability of these materials, the technique did have some shortcomings in analyzing these materials. The first was that sample mass of the liquids tested had some noticeable effects on the precision of the data collected. ILs do absorb water rapidly which changes their sample mass from a char yield and flammable mass perspective. Further, metering out 5-15mg ILs repeatedly for this test did prove difficult and likely led to some of the observed scatter in the data. Therefore some improvements in sampling would be needed to get better data for future ILs flammability studies.

To conclude, the use of PCFC enabled the quantification of heat release potential and gave some useful insight into chemical structure of ILs and their potential flammability. The chemical structure of the cation and anion of the ILs can have a big effect on heat release, and therefore one must not assume that all ILs are the same from a flammability perspective. The potential for some ILs to char may have some unexpected effects on flame spread, just as the potential for other ILs to fully gasify may also change what happens in a larger scale fire. Heat release is only one of many potential things to consider, and while it tells the fire safety engineer and chemist a great deal of information about flammability potential, it does to reveal everything. Clearly, more study is needed, but, heat release measurements like that from the PCFC are a place to start when making an assessment on the fire safety of this new technology.

\section{Conclusions and Perspectives}

In most cases, ILs have a lot advantages towards safer separation and purification processes compared to conventional solvents, and this is a fact that no one denies. But saying that ILs are safe by nature as a general statement can be seen as a hasty conclusion. There are some physicochemical safety issues and we should try to remove the misleading wordings such as "non flammability", "non volatility" since the recent literature refers to volatile decomposition of ILs. Corrosivity must be regarded as an important issue and chemical incompatibilities have to be 
considered. Like all new technologies, more time is needed to properly assess the strengths and weaknesses of this new technology, and better understand and assign safety performance parameters appropriate to the chemistry and physical properties of this new class of materials.

It seems also obvious from lectures that were given at the ILSEPT conference that the chemical structures play a major role in the value of heats of combustion (hence on physico-chemical issues) as well as toxicity and ecotoxicity issues. Some design techniques such as limiting the size of side chains on the cation part may in the same time favor the reduction of toxicity and flammability, but ultimately it will involve chemical research to establish the chemical structureproperty relationships that yield an IL with a favorable reactive, flammability, toxicity, cost and performance profile. Very likely future ILs will have a balance of properties and clear direction will be given on how that specific IL can and cannot be used relative to its physico-chemical properties.

It is also important to go beyond conventional hazard ratings for a better understanding of the physico-chemical properties of ILs. As discussed in the study, heats of combustion of ILs are often close or in the order of those of conventional combustible materials like wood, or plastics. Just as one does not compare all chemical compounds with the same metric, ILs must not be compared exactly with industrial solvents because they are very different chemicals. Certainly they have their advantages, but they are flammable and once it understood under what conditions they can burn, better fire safety assessments can be conducted. Fire hazards in processes have to be further investigated, because maybe those chemicals are not flammable due to the flashpoint, but in some processes or some applications we can have potential heats released that will serve to ignite them.

For that purpose, work has been initiated to develop a dedicated methodology to qualify risk profiles of ILs to be encouraged. Huge number of ILs dictates use of both experimentation and development of predictive tools using molecular modelling, and we believe some of the tools outlined in this paper, simple predictive heat of combustion modelling and the use of PCFC, could be a very good place to start in providing a more realistic heat release / fire risk profile for this new class of materials. 


\section{Reference}

[1] H.L. Ngo, K. LeCompte, L. Hargens, A. B. McEwen, Thermal properties of imidazolium ionic liquids, Thermochim. Acta 357-358 (2000) 97-102.

[2] P. Bonhôte, A.P. Dias, N. Papageorgiou, K. Kalyanasundaram, M. Grätzel, Hydrophobic, Highly Conductive Ambient-Temperature Molten Salts, Inorg. Chem. 35 (2011) 1168-1178.

[3] A.B. McEwen, H.L. Ngo, K. LeCompte, J.L. Goldman, Electrochemical Properties of Imidazolium Salt Electrolytes for Electrochemical Capacitor Applications, J. Electrochem. Soc. 146 (1999) 1687-1695.

[4] The European Commission Website on Registration, Evaluation, Authorisation and Restriction of Chemicals (http://ec.europa.eu/enterprise/sectors/chemicals/reach/index_en.htm) (Accessed July 2011).

[5] Regulation (EC) No 1272/2008 of the European Parliament and of the Council of 16 December 2008 on Classification, labelling and packaging of substances and mixtures, mending and repealing, European Parliament and of the Council, Directives 67/548/EEC and 1999/45/EC, and amending Regulation (EC) No 1907/2006. (http://eurlex.europa.eu/LexUriServ/LexUriServ.do?uri=CONSLEG:2008R1272:20101201:EN:PDF) (Accessed July 2011).

[6] M. Smiglak, W.M. Reichert, J.D. Holbrey, J.S. Wilkes, L. Sun, J.S. Thrasher, K. Kirichenko, S. Singh, A.R. Katritzky, R.D. Rogers, Combustible ionic liquids by design: is laboratory safety another ionic liquid myth?, Chem. Commun. (2006) 2554-2556.

[7] D.M. Fox, W.H. Awad, J.W. Gilman, P.H. Maupin, H.C. De Long, P.C. Trulove, Flammability, thermal stability, and phase change characteristics of several trialkylimidazolium salts, Green Chem. 5 (2003) 724-727.

[8] U. Schaller, T. Keicher, V. Weiser, H. Krause, S. Schlechtriem, Synthesis, Characterization and Combustion of Triazolium Based Salts, Insensitive munitions and energetic materials technology symposium, October 11-14, 2010, Munich, Germany.

[9] D.M. Fox, J.W. Gilman, A.B. Morgan, J.R. Shields, P.H. Maupin, R.E. Lyon, H.C. De Long, P.C. Trulove, Flammability and Thermal Analysis Characterization of Imadazolium-Based Ionic Liquids, Ind. Eng. Chem. Res. 47 (2008) 6327-6332.

[10]M. J. Earle, J.M.S.S. Esperanca, M.A. Gilea, J.N. Canongia Lopes, L.P.N. Rebelo, J.W. Magee, K.R. Seddon, J.A. Widegren, The distillation and volatility of ionic liquids, Nature 439 (2006) 831-834.

[11]P.S. Kulkarni, L.C. Branco, J.G. Crespo, M.C. Nunes, A. Raymundo, C.A.M. Afonso, Comparison of physicochemical properties of new ionic liquids based on imidazolium, quaternary ammonium, and guanidinium cations, Chemistry 13 (2007) 8478-8488.

[12] V. Kamavaram, R.G. Reddy, Thermal stabilities of di-alkylimidazolium chloride ionic liquids, Int. J. Therm. Sci. 47 (2008) 773-777.

[13] K.J. Baranyai, G.B. Deacon, D.R. MacFarlane, J.M. Pringle, J.L. Scott, Thermal Degradation of Ionic Liquids at Elevated Temperatures, Aust. J. Chem. 57 (2004) 145-147. 
[14]N. Meine, F. Benedito, R. Rinaldi, Thermal stability of ionic liquids assessed by potentiometric titration, Green Chem. 12 (2010) 1711-1714.

[15]T. J. S. Schubert, Ionic liquids as Thermal Fluids - Novel Structural Motifs, Presented at the 1st International Conference on Ionic Liquids in Separation and Purification Technology, Sitges, Spain, 4-7 Sept. 2011.

[16]K. Binnemans, How to select the best ionic liquid for a given application?, Presented at the 1st International Conference on Ionic Liquids in Separation and Purification Technology, Sitges, Spain, 4-7 Sept. 2011.

[17]P.G. Jessop, Searching for green solvents, Green Chem. 13 (2011) 1391-1398.

[18] A. Janes, G. Marlair, P. Rotureau, Biodiesel: a case study of the impact of new rules regarding the classification and labelling of physical and chemical properties of chemicals. $13^{\text {th }}$ International Symposium on Loss Prevention and Safety Promotion in the Process Industries, Brugge, Belgium, 6-9 June 2010.

[19] M.E.M. Berger, D. Assenbaum, N. Taccardi, E. Spiecker, P. Wasserscheid, Simple and recyclable ionic liquid based system for the selective decomposition of formic acid to hydrogen and carbon dioxide, Green Chem. 13 (2011) 1411-1415.

[20]A.E. Visser, R.P. Swatloski, W.M. Reichert, S.T. Griffin, R.D. Rogers, Traditional Extractants in Nontraditional Solvents: Groups 1 and 2 Extraction by Crown Ethers in Room-Temperature Ionic Liquids, Ind. Eng. Chem. 39 (2011) 3596-3604.

[21] S. I. Lall, D. Mancheno, S. Castro, V. Behaj, J.I. Cohen, R. Engel, Polycations. Part X. LIPs, a new category of room temperature ionic liquid based on polyammonium salts, Chem. Commun. (2000) 2413-2414.

[22]L. Gubicza, N. Nemestóthy, T. Fráter, K. Bélafi-Bakó, Enzymatic esterification in ionic liquids integrated with pervaporation for water removal, Green Chem. 5 (2003) 236-239.

[23]C.H. Tseng, J.K. Chang, J.R. Chen, W.T. Tsai, M.J. Deng, I.W. Sun, Corrosion behaviors of materials in aluminum chloride-1-ethyl-3-methylimidazolium chloride ionic liquid, Electrochem. Commun. 12 (2010) 1091-1094.

[24]T. Predel, Ionic Liquids as Operating Fluids in High Pressure Applications, Chem. Eng. Technol. 30 (2007) 1475-1480.

[25]T. Predel, E. Schlücker, Ionic Liquids in Oxygen Compression, Chem. Eng. Technol. 32 (2009) 1183-1188.

[26]I Perissi, U. Bardi, S. Caporali, A. Lavacchi, High temperature corrosion properties of ionic liquids, Corros. Sci. 48 (2006) 2349-2362.

[27] A. Brand, T. Hawkins, G. Drake, I. M.K. Ismail, G. Warmoth, L. Hudgens, Energetic Ionic Liquids as TNT Replacements. Presented at the 22nd Safety \& Environmental Protection Subcommittee (SEPS) Joint Meeting, Sandestin Beach, FL, 6-10 Mar 2006.

[28]J.L. Shamshina, M. Smiglak, D.M. Drab, T.G. Parker, H.W.H. Dykes Jr, R. Di Salvo, A.J. Reich, R.D. Rogers, Catalytic ignition of ionic liquids for propellant applications, Chem. Commun. 46 (2010) 8965-8967. 
[29]H. Gao, Y.H. Joo, B.Twamley, Z. Zhou, J.M. Shreeve, Hypergolic ionic liquids with the 2,2dialkyltriazanium cation, Angew. Chem. Int. Ed. Engl. 48 (2009) 2792-2795.

[30] Y.H. Joo, H. Gao, Y. Zhang, J.M. Shreeve, Inorganic or organic azide-containing hypergolic ionic liquids, Inorg. Chem. 49 (2010) 3282-3288.

[31] Y. Zhang, H. Gao, Y. Guo, Y.H. Joo, J.M. Shreeve, Hypergolic Dimethylhydrazinium Ionic Liquids, Chem. Eur. J. 16 (2010) 3114-3120.

[32]L. He, G.H. Tao, D.A. Parrish, J.M. Shreeve, Nitrocyanamide-based ionic liquids and their potential applications as hypergolic fuels, Chemistry 16 (2010) 5736-5743.

[33] T. Tsuda, C.L. Hussey. Electrochemical Applications of Room-Temperature Ionic Liquids, J. Electrochem. Soc. 16 (2007) 42-49.

[34]Q. Dong, C.D. Muzny, A. Kazakov, V. Diky, J.W. Magee, J.A. Widegren, R.D. Chirico, K.N. Marsh, M. Frenkel, ILThermo: A Free-Access Web Database for Thermodynamic Properties of Ionic Liquids, J. Chem. Eng. Data 52 (2011) 1151-1159.

[35] S.A. Channiwala, P.P. Parikh, A unified correlation for estimating HHV of solid, liquid and gaseous fuels, Fuel 81 (2002), 1051-1063.

[36]G. Marlair, C. Cwiklinski, A. Tewarson, An analysis of some practical methods for estimating heats of combustion in fire safety studies, Interflam. (1999), 201-212.

[37]F.Y. Hshieh, Predicting heats of combustion and lower flammability limits of organosilicon compounds, Fire Mater. 23 (1999) 79-89.

[38]F.Y. Hshieh, D.B. Hirsch, H.D. Beeson, Predicting heats of combustion of polymers using an empirical approach, Fire and Mater. 27 (2003) 9-17.

[39] W.G. Lloyd, D.A. Davenport, Applying thermodynamics to fossil fuels: Heats of combustion from elemental compositions, J. Chem. Educ. 57 (1980) 56-57.

[40] The expert group on quantitative structure-activity relationships (Q)SAR on the principles of validation of (Q)SARs, series on Testing and Assessment No. 49, Organisation for Economic Co-operation and Development 2004. (http://www.oecd.org/officialdocuments/publicdisplaydocumentpdf/?cote=ENV/JM/MONO( 2004)24\&docLanguage=En) (Accessed July 2011).

[41] A.O. Diallo, G. Fayet, C. Len, G. Marlair, Evaluation of heats of combustion of ionic liquids through use of existing and purpose-built models. Just accepted manuscript in Ind. Eng. Chem. Res., 2012. DOI

[42]R.N. Walters, R.E. Lyon, Molar Group Contributions to Polymer Flammability, J. App. Polym. Sci. 87 (2002) 548-563.

[43]R.E. Lyon, R.N. Walters, Pyrolysis combustion flow calorimetry, J. Anal. Appl. Pyrolysis 71 (2004) 27-46.

[44]B. Schartel, K.H. Pawlowski, R.E. Lyon, Pyrolysis combustion flow calorimeter: A tool to assess flame retarded PC/ABS materials?, Thermochim. Acta 462 (2007) 1-14.

[45]A.B. Morgan, M. Galaska, Microcombustion calorimetry as a tool for screening flame retardancy in epoxy, Polym. Adv. Technol. 19 (2008) 530-546. 
[46]J.M. Cogen, T.S. Lin, R.E. Lyon, Correlations between pyrolysis combustion flow calorimetry and conventional flammability tests with halogen-free flame retardant polyolefin compounds, Fire Mater. 33 (2009) 33-50.

[47]R.E. Lyon, M.T. Takemori, N. Safronava, S.I. Stoliarov, R.N. Walters, A molecular basis for polymer flammability, Polymer 50 (2009), 2608-2617.

[48]P.M. Hergenrother, C.M. Thompson, J.G. Smith, J.W. Connell, J.A. Hinkley, R.E. Lyon, R. Moulton, Flame retardant aircraft epoxy resins containing phosphorus, Polymer 46 (2005) 5012-5024.

[49] A.B. Morgan, Pyrolysis combustion flow calorimetry: a tool for flame retardant development and fundamental combustion science, Interflam (2010) 269-280. 